Accepted refereed manuscript of:

Banerjee S, Cason T, de Vries F \& Hanley N (2017) Transaction Costs, Communication and Spatial Coordination in Payment for Ecosystem Services Schemes, Journal of Environmental Economics and Management, 83, pp. 6889.

DOI: $10.1016 /$ j.jeem.2016.12.005

(C) 2017, Elsevier. Licensed under the Creative Commons AttributionNonCommercial-NoDerivatives 4.0 International

http://creativecommons.org/licenses/by-nc-nd/4.0/ 


\title{
Transaction Costs, Communication and Spatial Coordination in Payment for Ecosystem Services Schemes*
}

\author{
Simanti Banerjee \\ University of Nebraska-Lincoln \\ Email: simanti.banerjee@unl.edu \\ Timothy N. Cason \\ Purdue University \\ Email: cason@purdue.edu \\ Frans P. de Vries \\ University of Stirling \\ Email: f.p.devries@stir.ac.uk \\ Nick Hanley \\ University of St Andrews \\ Email:ndh3@st-andrews.ac.uk
}

December 2016

\begin{abstract}
Agricultural producer participation and spatial coordination of land use decisions are key components for enhancing the effective delivery of ecosystem services from private land. However, inducing participation in Payment for Ecosystem Services schemes for coordinating land management choices is challenging from a policy design perspective owing to transaction costs associated with participation. This paper employs a laboratory experiment to investigate the impact of such costs on participation and land use in the context of an Agglomeration Bonus (AB) scheme. The AB creates a coordination game with multiple Nash equilibria related to alternative spatially-coordinated land use patterns. The experiment varies transaction costs between two levels (high and low), which affects the risks and payoffs of coordinating on the different equilibria. Additionally, an option to communicate is implemented between neighboring producers arranged on a local network to facilitate spatial coordination. Results indicate a significant difference in participation and performance under high and low transaction costs, with lower uptake and performance when transaction costs are high. These effects are, however, impacted by transaction costs faced in the past. Communication improves both $\mathrm{AB}$ participation rates and performance with the effect being greater for participants facing high transaction costs.
\end{abstract}

Keywords: Agglomeration Bonus, Payments for Ecosystem Services, Content Analysis, Coordination Games, Lab Experiments, Local Networks, Strategic Uncertainty

\footnotetext{
${ }^{*}$ We thank the European Investment Bank (EIB) for financial support under the EIB-University Research Action Programme (theme Financial and Economic Valuation of Environmental Impacts). The findings, interpretations and conclusions presented are entirely those of the authors and should not be attributed in any manner to the EIB. Any errors remain those of the authors. For helpful comments we thank Hernan Bejarano, Daniel Hellerstein, Gregory Parkhurst, Andrew Reeson and two anonymous referees; seminar participants at the University of Aberdeen, Indiana University, University of Michigan, Technical University Munich, Murdoch University, University of Montpellier, and audiences at the Annual BIOECON and Economic Science Association conferences. We also thank Ashlee Carlson, Mike Castle and John Bohaty for valuable research support.
} 


\section{Introduction}

Payment for Ecosystem Services (PES) or agri-environmental schemes offer agricultural producers financial incentives for actions designed to increase the supply of ecosystem services from privately owned land (Hanley et al. 2012; Hanley and White 2014). In many instances, spatial coordination is a desirable feature of such schemes, enabling the delivery of greater ecosystem service benefits compared to a situation where the uptake of contracts is spatially uncoordinated. Examples include greater biodiversity conservation benefits on farmland (Merckx et al. 2009; Dallimer et al. 2010; Wätzold et al. 2010), successful species reintroduction programmes and meta-population management on private land where habitat corridors permit wildlife movements, or where certain minimum sized contiguous habitat is needed (Williams et al. 2005; Önal and Briers 2006), enhanced water quality improvements (Lane et al. 2004; Lane et al. 2006), and native vegetation restoration (Windle et al. 2009).

Since participation in PES schemes is voluntary, economists have looked for tools to incentivize spatial coordination. One such option is the Agglomeration Bonus (AB), originally developed by Parkhurst et al. (2002). The AB is a two-part payment mechanism where producers receive compensation for participating/enrolling in a PES-type programme, plus a bonus if neighboring agricultural producers participate and select the same land use activity. In this format, the $\mathrm{AB}$ resembles a coordination game with multiple Nash equilibria pertaining to different land use choices. These Nash equilibria can be Pareto ranked by their payoffs. Laboratory experiments have indicated that such a payment structure can produce a range of desired spatial patterns of enrolled land parcels (Parkhurst and Shogren 2007; Warziniack et al. 2007). However, Banerjee et al. (2012; 2014) found that spatial coordination is challenging, and the AB can often fail to produce the desired spatial patterns owing to coordination failure.

Participation in any PES scheme incurs transaction costs for the producers (Shortle et al. 1998; Kampas and White 2004). Examples of such costs include producers' travel time to meetings with government officials, the time and cognitive effort of determining the relative payoffs of signing or not signing a contract, and the costs of engaging farm and ranch advisors. Such transaction costs have been shown empirically to reduce participation in PES schemes (Falconer and Saunders 2002; McCann et al. 
2005; Mettepenningen et al. 2009). The AB, with its more complex design, is likely to create additional transaction costs such as those associated with negotiating with neighbors. It seems likely then that the success of the $\mathrm{AB}$ will be influenced by the size of transaction costs relative to the payoffs of enrolling. Yet no analysis to date has studied the effects of variations in transactions costs on AB performance. Fooks et al. (2016) is perhaps closest to our study, in which the transaction costs are implicitly captured by a fixed submission fee. However, they study a conservation auction and not a subsidy scheme.

Our paper poses two research questions. First, what is the degree of participation and spatial coordination realized in $\mathrm{AB}$ schemes under different levels of transaction costs? Second, to what extent can communication between neighboring producers improve $\mathrm{AB}$ performance given these transaction costs? We answer these questions using a laboratory experiment. Lab experiments are useful to this study because they bypass the fact that it is not practical, and often even impossible, to exogenously manipulate the size of transaction costs for PES scheme participation in the field; and because only a few PES schemes in practice today include payments for spatial coordination (Kuhfuss et al. 2016). By implementing a predefined fixed network structure in the laboratory, thus keeping the environmental complexity constant, the experiment allows us to specifically investigate how varying transaction costs impact spatial coordination within an $\mathrm{AB}$ setting.

Our experiment is comprised of groups of subjects who decide whether to participate in an $A B$ scheme by paying a fixed fee - the transaction cost of participation. The transaction cost treatment is manipulated in a within-subject design. Since we are interested in strategic interactions and spatial coordination, we use a circular local network. On this type of network every individual is connected to two neighbors (to their left and to their right) directly whilst being indirectly connected to everyone else (Jackson 2010). While serving as a suitable framework reflecting the decision problems of land managers on real landscapes, this network structure also allows us to contribute to the experimental literature on equilibrium selection and individual behavior in network coordination games (Berninghaus et al. 2002; Cassar 2007). The network is also useful for implementing our between-subject costly communication treatment in a format representative of social interactions in agricultural communities where 
communication incurs a transaction cost and is expected to be more frequent between geographical neighbors than with other community members. ${ }^{1}$

Our results indicate that transaction costs are a problem for participation only, with uptake being significantly lower when transactions costs are higher. Yet, conditional on participation, these costs don't matter to the extent that there is no significant difference in rates of efficient spatial coordination under high and low transaction costs. The role of communication is not straightforward. Messaging unambiguously improves performance relative to no-communication situations when transaction costs are high (as it helps to resolve game strategic uncertainty). However, its efficacy in low transaction cost regimes depends upon whether subjects faced high costs in the past when participating in the AB scheme.

\section{The Strategic Environment}

There are $i=1, \ldots, N$ agricultural producers who face two simultaneous decision opportunities. The first decision entails whether or not to participate in the $\mathrm{AB}$ scheme. If a producer decides to participate, he or she can use their land for two different types of land uses, $\sigma_{i}=X, Y$, which produce different levels and types of ecosystem services benefits. Our choice decision is thus at the extensive margin and different from the original setup proposed in Parkhurst and colleagues $(2002,2007)$ where subjects make an intensive margin choice of how many acres to enrol. We have made this distinction so that our results may prove insightful for understanding choices facing actual landowners in a PES scheme where enrolment options are "all or nothing", such as in the Conservation Stewardship Program in the US under which the entire eligible acreage has to be enrolled in specific land uses to receive payments (NRCS 2016).

We assume that the ecosystem service benefits delivered from coordination of land use type $X$ have greater agglomeration rewards than for type $Y$, and the regulator sets the $\mathrm{AB}$ payments to reflect this

\footnotetext{
${ }^{1}$ In the field, transaction costs and costs of communication might vary with the degree of environmental complexity owing to individual and landscape heterogeneity (e.g., due to the amount and nature of land holdings, the number of landowners, or the extent of their social capital). However, the dynamics of these factors can make it difficult to isolate the treatment effects. Thus, we have controlled the transaction cost and communication cost to be the same for everyone, eliminating the possibility of confounding.
} 
ranking. Such differences in environmental benefits from spatial coordination of enrolment might reflect differences in the ecological objectives of a scheme, or in the kinds of land use changes that are rewarded. Let $\sigma_{i}=N P$ denote non-participation for producer $i$ whereby land is devoted to profit-based conventional agriculture, earning only agricultural returns. ${ }^{2}$

The $\mathrm{AB}$ scheme consists of two payoff components. The base component is a participation subsidy, $s\left(\sigma_{i}\right)$, intended to compensate for any opportunity cost of conservation relative to profitmaximising agricultural land use. Producer $i$ receives an additional bonus, $b\left(\sigma_{i}\right)$, if a neighboring landowner implements the same conservation land use practice as them. Thus, the total bonus received is proportional to the number of neighbors choosing the same land use strategy, denoted by $n_{i \sigma}$. We assume that the environmental agency provides $\mathrm{AB}$ payments for adoption of pro-conservation land use of one type only, i.e., producers cannot choose both $X$ and $Y$. We make this assumption because (i) PES schemes typically involve a menu of land use practices from which producers usually can select a few suitable ones, and (ii) paying some landowners for undertaking all listed actions may exhaust the limited PES budget (Cooper, Hart, and Baldock 2009; Armsworth et al. 2012), creating high participation clusters in some areas at the expense of low participation rates elsewhere. ${ }^{3}$ Let $r\left(\sigma_{i}\right)$ denote the agricultural revenue under land use $\sigma_{i}=X, Y, N P$.

If a producer $i$ chooses to participate in the scheme he or she incurs transaction costs, $T_{i}$. We assume that everyone has identical transaction costs, i.e., $T_{i}=T$, which are either High or Low depending on the treatment. In practice, these costs will vary substantially across producers and across land use strategies. However, by sacrificing some realism (which would probably not cause large behavioral differences) we gain tractability to identify causal treatment effects. The payoff, $u_{i}\left(\sigma_{i}\right)$, of producer $i$ under the $\mathrm{AB}$ scheme reads as follows:

\footnotetext{
${ }^{2}$ Traditional agricultural land use practices (denoted by $N P$ ) can also deliver ecosystem services such as reduction in soil erosion and biodiversity benefits by providing nesting and foraging habitats. These benefits are, however, not additional as they are associated with business-as-usual land use practices. Since one of the criteria for receiving ecosystem services payments is additionality (Wunder 2007; Engel et al. 2008), such benefits should not be rewarded by the conservation agency. We therefore do not consider them in our model.

${ }^{3}$ Such localized clustering may be interpreted as geographical targeting of conservation funds which can be politically contentious to the extent that the U.S. Congress prohibited such targeting (Shortle et al., 2012).
} 
$u_{i}\left(\sigma_{i}\right)= \begin{cases}r\left(\sigma_{i}\right)+s\left(\sigma_{i}\right)+n_{i \sigma} b\left(\sigma_{i}\right)-T & \text { if } \sigma_{i}=X, Y \\ r\left(\sigma_{i}\right) & \text { if } \sigma_{i}=N P\end{cases}$

In Eq. (1) the number of neighbors and hence the bonus payment is contingent on the specific landscape structure. Following Banerjee et al. $(2012,2014)$, in this study we impose a simple circular network structure to represent neighborhood interactions. On such a circular local network $n_{i \sigma}$ can either take the value 0,1 or 2 . By employing a circular network each individual faces the same level of strategic uncertainty within the decision environment, since all have the same number of neighbors. ${ }^{4}$ Given this spatial symmetry in terms of network location, we avoid additional complications such as holdout problems due to bargaining power of some individuals who are strategically located. In networks featuring an asymmetric neighborhood structure (e.g., a two-dimensional lattice grid or a straight-line), individuals could respond differently to the transaction cost variation and information available through communication.

We note here that while the choice of network structure is simpler than the more complex spatial grids implemented by Parkhurst et al. (2002) and Parkhurst and Shogren (2007), it still captures the main strategic interdependencies that are relevant for studying spatially contiguous land use. First, in many realistic environments, individuals typically do not interact with all individuals within their network directly but perhaps only interact with a few closely linked peers who provide them with information about what others within the same network are doing. Second, like more complex spatial grids, a circular network also exhibits strategic uncertainty regarding individuals' decisions, especially if individuals have imperfect information about the choices of those who are not their direct neighbors (see Banerjee et al., 2014). In that sense, while simple, our strategic setting is relevant to studying PES institutions. The payoff function specification in Eq. (1) makes the $A B$ mechanism a coordination game with Nash equilibria pertaining to situations where individuals and their neighbors choose the same land use strategy.

\footnotetext{
${ }^{4}$ Strategic uncertainty refers to uncertainty concerning the purposive behavior of players in an interactive decision situation, which arises due to the existence of multiple equilibria in a strategic game (Van Huyck et al. 1990 1991; Heinemann et al, 2009).
} 
The $\mathrm{AB}$ coordination game has a Pareto efficient and multiple risk dominant Nash equilibrium strategies (Harsanyi and Selten 1988; Parkhurst et al. 2002). Strategy $X$ corresponds to the Pareto efficient strategy as it generates the highest payoffs (because it has the greatest environmental benefits and hence highest agglomeration bonus). Strategy $Y$ on the other hand constitutes a situation of coordination failure explained by the presence of strategic uncertainty within the game environment. That is, it might be less risky for a subject to choose the land use practice $Y$ as it corresponds to a lower payoff loss in the event that one or more neighbors choose not to coordinate on the efficient strategy $X$. Strategy $N P$ is also an equilibrium strategy which does not involve participating in the $\mathrm{AB}$ scheme. This coordination game is similar to critical mass coordination games where the payoff from choosing an action is positive only if a specific number of players also choose that action (Devetag 2003).

In the context of the $\mathrm{AB}$ mechanism, Appendix B.I contains all parameters that have been used to construct the Payoff Tables 1a and $1 \mathrm{~b}$ for the High $(T=40)$ and Low $(T=15)$ transaction cost treatments, respectively. The $\mathrm{AB}$ payments for $X$ and $Y$ are chosen to reflect the fact that ecosystem services generated through adoption of $X$ land use are spatially contingent to a higher degree than those generated through $Y$. For example, $X$ can correspond to land uses leading to a reduction of habitat fragmentation. Here, the location of adopted use matters much more than in the situation where land use involves reduction in fertilizer use where the number of adoptees may matter more than their location. The value of the high transactions cost is chosen such that the game has two Nash equilibria: $\sigma_{i}=X(\forall i)$ and the outside option $\sigma_{i}=N P(\forall i)$ with the former one Pareto dominating the latter. Choosing land use practice $Y$ is not a Nash equilibrium because it is strictly dominated by $N P$. Therefore, if a subject chooses to pay the fee and participate in the scheme, he or she would be likely to choose $X$ over $Y$. The high transaction cost thus eliminates the coordination problem in the event of participation.

In fact, the high cost can also be interpreted as a form of signalling, credible costly communication or tacit-communication (Blume and Ortmann 2007), and combined with forward induction can reduce the strategic uncertainty associated with the presence of multiple Nash equilibria and 
guide behavior towards the efficient $X$ choice (Blume and Ortmann 2007). ${ }^{5}$ In contrast, for the low transaction cost setting, selection of $Y$ by a landowner and both direct neighbors leads to a payoff which is not strictly dominated by the reservation payoff, yielding a third Nash equilibrium $\sigma_{i}=Y(\forall i)$. This Nash equilibrium is risk dominant relative to the Pareto dominant Nash equilibrium $\sigma_{i}=X(\forall i)$. Although forward induction is no longer applicable in this setting, the low transaction cost can still serve as a cheaper form of costly communication reducing the underlying strategic uncertainty of the game and focusing subjects' attention on the efficient $X$ strategy. These conjectures are along the lines of theory presented by Hurkens (1996) in which the prospect of incurring a cost before game play can facilitate coordination on the efficient Nash equilibrium outcome. In our game the subjects have to incur the cost to move to the $\mathrm{AB}$ game stage, which may strengthen the ability of the transaction cost induced costlycommunication mechanism to generate participation and efficient coordination.

Further, for the high transaction cost setting, $T$ is greater than the participation payment for strategy $X$ only. We chose this format because if the transaction cost is less than the participation components for both $X$ and $Y$, participation is trivially incentivized even in the presence of the transaction cost and in the absence of the bonus. This is not an interesting case. The high cost $T$ value is also not set to be greater than the participation payments for both strategies because this feature would further reduce landowner appeal to participate in the $\mathrm{AB}$ scheme. Under the low cost condition, the transaction cost value is less than the participation component for both $X$ and $Y$ to generate a situation where participation is individually rational. We did not set $T$ to be greater than both the participation components for reasons similar to those for the high-cost environment. Finally, setting the low value of $T$ to be greater than the participation component for any one of the strategies would have been interesting but we decided to consider a scenario where incentives to participate are enhanced since, in the high-cost setting, participation barriers are substantial. Given this setup, we have two hypotheses:

\footnotetext{
${ }^{5}$ Forward induction involves making an inference about the future play in a subgame based on information about play leading up to the subgame (Van Huyck et al. 1993; Cooper et al. 1994; Cachon and Camerer 1996; Plott and Williamson 2000; Dufwenberg et al. 2016)
} 
HYPOTHESIS I: (TC1) Participation levels are lower in the high transaction cost treatment compared to the low transaction cost treatment.

HYPOTHESIS II: (TC2) Conditional upon choosing to participate, choice of the Pareto efficient equilibrium action is more frequent in the high transaction cost treatment compared to the low transaction cost treatment.

Additionally, the individual's land use choice, and hence the ability of the AB scheme to reach the efficient outcome and maximize ecosystem services benefits, is influenced by the degree of community-level communication and interactions. This is especially important in PES schemes where producers need to spatially coordinate their decisions (Lawley and Yang 2015). Communication can provide an opportunity to $(i)$ announce and declare sustained commitment for a particular action, (ii) articulate reasons for having made a choice in the past as well as those which will guide future decisions, (iii) influence direct neighbors to choose the same strategy, and (iv) persuade direct neighbors to convince other social peers to make the same choice. More generally, in coordination games with strategic uncertainty, communication can reduce variation in game outcomes and promote the play of the efficient Nash equilibrium strategy by making it focal (Blume and Ortmann 2007). Thus, communication can lead to a higher program uptake, reduce or avoid coordination failure, and improve the ability of the $\mathrm{AB}$ scheme to generate the Pareto efficient outcome as has been presented by Parkhurst et al. (2002) and Warziniack et al. (2007), and in more general settings by Charness (2000). Warziniack et al. (2007) also find that pre-play communication reinforces producers' decisions to reach the Pareto efficient outcome quickly. Yet, in a conservation auction with AB payments, Fooks et al. (2016) find that communication may lead to collusion and higher rent extraction. ${ }^{6}$ Similarly, in more general designs the efficiencyenhancing role of pre-play communication is weak (Clark et al. 2001).

\footnotetext{
${ }^{6}$ Note that Parkhurst et al. (2002), Warziniack et al. (2007) and Fooks et al. (2016) focus on spatial targeting, i.e., how agglomeration bonuses - both with and without communication - can promote the establishment of pre-
} 
The impact of communication is thus predicated on the nature of the strategic environment, as has also been established by Duffy and Feltovich (2002). Hence, it is important to study the role of communication on $\mathrm{AB}$ outcomes in settings such as the current one. Additionally, in all the previous $\mathrm{AB}$ studies, communication was assumed to be costless and introduced as an exogenous treatment variable. However, communication typically incurs costs; for example, the time spent calling or visiting neighbors. Given that transaction costs of $\mathrm{AB}$ participation are analogous to costly communication mechanisms, it is realistic that we incorporate explicit communication opportunities in a costly format into the decision environment. Moreover in our model the presence of costly communication is interesting for the high transaction cost setting where there is no coordination problem post-participation and the only bottleneck is the participation hurdle. ${ }^{7}$ Yet, the messaging fee could also serve as an impediment because it increases the total costs of communication (when combined with the transaction costs of program participation). Thus, many subjects may not want to incur this additional fee and hence the benefits of communication may not be realized. Correspondingly, our third hypothesis is:

HYPOTHESIS III (Communication): Communication opportunities between neighboring landowners leads to (a) higher participation levels, and (b) given participation, improves coordination on the Pareto efficient equilibrium.

\section{Experimental Design and Procedures}

We report data from 24 sessions with 8 subjects per session, as summarized in Table 2, producing a data set with 192 subjects. Each experimental session was divided into two phases consisting of 15 periods each. In Phase I for 12 sessions termed HLTC (abbreviating High-Low Transaction Cost), subjects faced the high transaction cost of 40, followed by the low cost of 15 in Phase II. In the remaining 12 sessions

determined land use configurations across space. In this paper we do not investigate spatial targeting and concentrate on the general coordination problem of achieving the efficient land use on a given spatial network of producers.

${ }^{7}$ Note that we chose the value of the messaging fee such that the Nash equilibrium strategies under the two transaction cost conditions are the same in the no-communication and communication settings. 
termed LHTC (abbreviating Low-High Transaction Cost), the cost ordering was reversed. We implemented this within-subject variation $(i)$ because transaction costs associated with the same economic decision may change over time, (ii) to minimize within-subject variation for comparison across treatments, and (iii) to study behavior of inexperienced subjects and those with some prior experience with a transaction cost value. Non-binding pre-play communication, denoted by COMM, was implemented as a between-subject treatment in 8 of the 24 sessions. ${ }^{8}$ Subjects could communicate privately in chat windows with adjacent neighbors by paying a fee of 5 experimental francs per neighbor. ${ }^{9}$ Subjects could receive messages from neighbors for free despite having chosen not to communicate. This communication protocol is similar to the one implemented in Cooper et al. (1989) and represents the reality that communication is almost always costly for the sender whereas receiving messages (an email, voicemail or written communication) incurs minimal cost.

At the beginning of the experiment, every subject received a randomly-assigned ID that determined their location and their networked neighbors' identities. This ID remained the same in Phase I. We implemented this fixed-matching protocol because private land ownership and operation is usually unchanged for long time periods and also because repeated interactions with the same set of subjects can foster coordination by building subjects' reputation for playing a particular strategy amongst their direct neighbors. At the beginning of Phase II the neighborhood structure was shuffled and every subject received a new ID and a new set of neighbors which remained unchanged henceforth. This ID switch was implemented to break any possible path dependence that is often present in coordination game experiments (Van Huyck et al. 1993; Romero 2015). This path dependence can confound the transaction cost variation treatment when transitioning from Phase I to Phase II. During each phase of the experiment, subjects received hand-outs (see Appendix B.II) containing information on the payoffs, the transaction

\footnotetext{
${ }^{8}$ We also ran 4 sessions for both cost orderings (8 in total) where communication was free so that the costs of communication were essentially identical to the baseline sessions (termed NO-COMM) with tacit communication.

${ }^{9}$ We kept chat windows open for 60 seconds to ensure that even if subjects chatted in all 30 periods, the experiment would not last for more than 90 minutes beyond which subject fatigue might compromise the quality of responses.
} 
cost of participation associated with that phase (15 or 40), the reservation (non-participation) income (175), and a figure representing their positions on the network.

In the COMM treatment, at the beginning of a period, subjects first decided whether they wanted to pay the fee to communicate with their neighbors. Those who chose not to pay the fee waited for others to finish chatting. After this stage, everyone made their participation decisions. In the NO-COMM sessions, everyone proceeded to the participation stage directly. In this stage each subject had to decide whether to participate in the $\mathrm{AB}$ scheme by incurring the transaction cost. Neighbors' participation decisions were not revealed while subjects made this decision. ${ }^{10}$ Individuals who chose to participate moved on to the next stage in which they selected land use $X$ or $Y$. Those who did not participate earned the reservation income.

Once all subjects made choices they received information about their own and their direct neighbors' communication decisions, participation, land use choices and payoffs for the current period. Additionally, an on-screen history table provided this information for all past periods within a phase. In the COMM sessions, this History table also included subjects' own and neighbors' current and past communication decisions, and the total fees paid to communicate.

We used content analysis methodology to analyze all messages from the COMM sessions. Three undergraduate students from the University of Nebraska-Lincoln reviewed chat content incorporated in 195 different chat rooms representing both dialogues and monologues. Rather than classifying individual chat sentences separately, all messages within a chat room were encoded jointly and classified into different categories on the basis of a message classification scheme. The classification scheme was developed on the basis of review of two randomly drawn COMM sessions (one for each transaction cost ordering). The content of each chat room could be assigned to multiple categories. In order to minimize bias, the research assistants coded statements without being aware of the research questions and did not interact with each other during this exercise.

\footnotetext{
${ }^{10}$ This approach allowed us to retain the simultaneous move feature of the coordination game although it comprised of two stages of decision-making.
} 
Since the coding is subjective, we measured inter-rater agreement using Cohen's Kappa (Cohen 1960; Krippendorff 2004). This is a scaled measure of agreement and takes a value of 0 when the agreement between coders is implied by random chance and 1 when the coders agree perfectly. Kappa values between 0.41 and 0.60 indicate that coders have Moderate agreement for that category, those between 0.61 and 0.8 indicate Substantial agreement and beyond that implies Almost Perfect agreement (Landis and Koch 1977). Table 3 presents a sub-set of categories from the message classification scheme which were coded with Moderate and higher reliability. ${ }^{11}$

The experiment was implemented in z-Tree (Fischbacher 2007) and subjects were recruited from the broad undergraduate Purdue University population using ORSEE (Greiner 2015) during August 2013 and November 2014. All experiment instructions (included in Appendix B.III) were made available on subjects' computer screens. We did not include any contextual terminology relevant to ecosystem services provision other than land use because we wanted to study how financial incentives impact experimental outcomes and also because pro-environmental terminology can potentially trigger various subject behaviors and confound the treatment effect (Cason and Raymond 2011).

Experiment instructions indicated that all subjects would be facing the same payoff table, that all $\mathrm{AB}$ scheme payoffs were net of the transaction costs of participation, and that the experiment would last for 30 periods. $^{12}$ Before starting the experiment, subjects participated in a quiz to verify their understanding. The sessions lasted between 60 and 90 minutes. Subjects were paid a $\$ 6$ show-up fee and additional money earned during the experiment. An exchange rate of US\$1 for 250 experimental currency (francs) was used to convert earnings, and average subject earnings (including the show-up fee) were $\$ 26.82$.

\footnotetext{
${ }^{11}$ We did consider other categories and sub-categories in our analysis, but they were coded with less than "Moderate" agreement and hence are not presented in the paper.

${ }^{12}$ To ensure that subjects knew that all payoffs were net of transaction costs, we clearly indicated their total payoff for each outcome in the experimental handout provided to them.
} 


\section{Experimental Results}

The results focus on the role of transaction costs and communication on (a) participation levels in the $\mathrm{AB}$ scheme, (b) the rates of efficient land use choice, and (c) the degree of spatial coordination on the efficient land use choice. ${ }^{13}$ In Section 4.1, we present the results related to the first two aspects followed by the findings pertaining to spatial coordination in Section 4.2 .

\subsection{Participation and Efficient Land Use Choices}

Consider first the findings from the non-communication (NO-COMM) sessions. The top two panels of Figure 1 present the participation rates in the two 15-period phases for both the cost treatments pooled across the 16 NO-COMM sessions. Participation rates are always higher under low transaction costs in both Phases of the experiment. These rates fall steadily from $70 \%$ in Period 1 to $20 \%$ in Period 15 in the HLTC-NO-COMM sessions. By contrast, subjects in LHTC-NO-COMM sessions are able to maintain relatively higher levels of participation with only a weak negative trend in Phase I. A nonparametric Wilcoxon Mann-Whitney test based on session-level average rates of participation in Phase I indicates a statistically significant treatment effect at the $5 \%$ level $(p$-value $=0.015) .{ }^{14}$ Thus, high transaction costs prove to be a deterrent for participation in the $\mathrm{AB}$ scheme, providing support for Hypothesis I. While this result is intuitive it is interesting to note that even if the high cost can generate forward induction tendencies (since conditional on participation, no coordination problem exists) and serve as a coordination mechanism, relative to low cost settings, it does not end up doing so. The weak negative trend for the low-cost setting indicates that transaction costs are less problematic at low values for $\mathrm{AB}$ scheme participation. Taken together these findings indicate that the effect of tacit communication

\footnotetext{
${ }^{13}$ The $Y$ land use (although not payoff efficient) is valuable for delivery of ecosystem services benefits, but is spatially explicit to a lesser degree in our model as reflected by the lower AB payment. However, our results focus on the participation and payoff efficient $X$ choices because of the low frequency of $Y$ choices in our experimental data (presented in Figure I in Appendix A), which makes it difficult to draw confident conclusions about $Y$ land use for the current setting.

${ }^{14}$ All nonparametric tests reported in the paper employ independent 8-person groups as the unit of observation.
} 
is weak in promoting participation in our local network AB setting, a finding similar to Clark et al. (2001) as mentioned previously.

Result 1: High transaction costs can significantly reduce participation rates in the AB schemes.

The falling rates of participation across repeated interactions under both cost conditions may be attributed to factors that resolve subjects' strategic uncertainty (in favor of non-participation) and impact the likelihood of participation. First, unlike in a non-network coordination game, both direct and indirect neighbors influence payoffs but only past choices of direct neighbors are visible. The second factor is that, given the structure of the payoffs, participation and subsequent coordination on $X$ is profitable only when both direct neighbors participate. This feature is true for both high and low transaction cost values, but losses induced by coordination failure are greater when costs are high. ${ }^{15}$

The experiment's two treatment phases are useful for evaluating how subjects' prior experience with a particular transaction cost regime affects participation. After the cost treatment switchover, in the HLTC-NO-COMM treatment the participation rate jumps substantially from $20 \%$ in Period 15 to nearly $86 \%$ in Period 16. This increase is statistically significant (Wilcoxon matched-pairs signed-rank test $p$ value $=0.013)$. The corresponding change from $78 \%$ to $80 \%$ for the LHTC-NO-COMM group is not statistically significant (Wilcoxon matched-pairs signed-rank test $p$-value $=0.943$ ). This result suggests a path dependence in outcomes for this treatment. Focusing on overall trends across all Phase II periods, we observe only a small decrease in participation in the HLTC-NO-COMM from $85 \%$ in Period 16 to $78 \%$ in Period 30. For the LHTC-NO-COMM treatment, a fall in program uptake occurs from $79 \%$ in Period 16 to $36 \%$ in Period 30 . However, no significant difference exists in participation rates between the HLTC-

\footnotetext{
${ }^{15}$ We adopted this feature to evaluate the performance of the $A B$ scheme in an adverse payoff setting with the expectation that if the incentive scheme performs well in the current environment, it will perform even better in scenarios where efficient coordination is profitable even if only some neighbors choose $X$. Moreover, this adverse payoff situation also reflects recent reductions in PES scheme budgets overall, which require resources to be spread thinly over numerous existing programs (Claassen and Ribaudo 2016; Shortle et al. 2012).
} 
NO-COMM and LHTC-NO-COMM groups in Phase II (Wilcoxon Mann-Whitney test $p$-value $=0.14$ ).

To summarize:

Result 2: Prior experience with low transaction costs reduces the negative impact of a transaction cost increase on future participation rates, moderating the effect of transaction costs as an obstacle for participation.

Figure I in Appendix A shows the percentage of $X, Y$ and $N P$ choices for both treatments for all periods. We observe $21 \%$ of $Y$ choices when transaction costs are low and only $4 \%$ when costs are high in the NO-COMM groups. Thus, conditional on participation, most subjects select the efficient $X$ strategy. ${ }^{16}$ The top panel of Figure II in Appendix A displays the percentage of $X$ choices conditional on participation for both phases for both cost treatments for the 16 NO-COMM sessions. Wilcoxon MannWhitney tests indicate no significant difference in the rate at which $X$ is chosen between high and low cost costs groups in both Phases I $(p$-value $=0.461)$ and Phase II $(p$-value $=0.368)$. Accordingly, our data do not provide support for Hypothesis II. Thus, while the transaction cost a priori is a deterrent for participation (with the high cost creating a bigger hurdle than the low cost), it does not hinder the AB's ability to incentivize efficient $X$ choices by subjects who indeed participate. This result is true independent of subject experience.

Next consider participation rates and efficient land use choice $X$ in the COMM sessions. The two bottom panels of Figure 1 display participation rates for the 8 COMM sessions under the two transaction cost ordering treatments for all periods across both phases. No discernible time trend exists in any phase, and the participation is always greater than $70 \%$ and higher when transaction costs are lower (after few initial periods). For an understanding of these outcomes, we analyze the nature of communication.

16 Concerning the frequency of $Y$ choices, Wilcoxon Mann-Whitney tests indicate a marginally significant transaction cost treatment effect $(p$-value $=0.052)$ in Phase I and at a 5\% level of significance $(p$-value $=0.047)$ in the latter part of Phase II of the NO-COMM sessions (after Period 20). 
Figure 2 presents information on chat frequency, indicating that despite adding to the total transaction costs incurred, subjects utilized communication opportunities under both cost conditions. Of the 195 chat rooms used, there is a predominance of dialogues (69 instances constituting 138 chat rooms) rather than monologues (57 chat rooms) under all conditions except in Phase I of the LHTC-COMM sessions. This is not surprising as dialogues are a more credible form of communication that can reduce strategic uncertainty and lead to more efficient outcomes, as has been found in two-player coordination games studied by Cooper et al. (1992) ${ }^{17}$ In the case of a monologue however the messaging player has no way of knowing if the receiver will respond appropriately. Blume (1998) notes here that, in games with costless one-way communication, in order for strategic uncertainty to be successfully resolved in favor of the efficient strategy, the sender's message should be self-signaling to the receiver; i.e., the receiver should believe that the sender is being truthful about message content. Similarly for the sender, the message needs to be self-committing, in that knowing that there is a high chance that the receiver is going to believe the content of the message, the sender will follow through with what he or she communicated. The presence of the messaging fee in our study (and the high and low transaction costs incurred subsequently) potentially reinforces this self-committing and self-signaling behavior and thus elevates the credibility of messages conveyed through monologues, both for the senders and receivers. ${ }^{18}$

Focusing on the timing of communication, Figure 3 indicates that most messaging occurs in the early periods of both Phase I (nearly $65 \%$ of all chat rooms) when subjects are unfamiliar or have low levels of experience in the experiment and early in Phase II (remaining 35\%) when subjects are reassigned to new neighbors. Such behavior is to be expected given the costly messaging setting because once coordination on a particular strategy has been established most subjects would rather only pay the

\footnotetext{
${ }^{17}$ A key point to consider here is that when subjects exchange messages with their neighbors on the local network, it is possible that they receive conflicting messages about which $\mathrm{AB}$ game action to choose. In this situation the power of communication to reduce strategic uncertainty and to lead to efficient coordination may be reduced (Blume 1998). Yet the subsequent transaction cost stage (serving as a coordination mechanism) and fixed matching can help resolve problems with such conflicting messaging, increasing the likelihood of efficient coordination.

${ }^{18}$ Note that the findings in Blume (1998) are based on a restrictive message space, unlike in this paper where we allow rich communication. Blume's theory is also based on randomized matching where there is a high chance that a large message space may lead to mis-coordination and coordination failure. In our study, fixed matching within a Phase, repeated interactions and learning builds reputation and familiarity in the game and reduces the chances of mis-coordination, despite a large message space.
} 
transaction cost and rely on information feedback after every period to sustain participation and the efficient strategy choice.

Turning to the communication content, Table 3 presents the Cohen's Kappa values and the relative frequency of the different categories and sub-categories into which the messages were classified. The most common category coded is "Influence neighbors to choose Strategy $X$ " (Category 4X) with a frequency of $44 \%$; i.e., in $44 \%$ of the chat rooms, a subject tried to influence a neighbor to select strategy $X$ by sending a message such as "Pick $X$ and we all win big". Moreover, across all COMM sessions we find that in 72 out of the 99 cases when subjects sent messages classified in this way, the neighbor receiving the communication selected $X$.

The second most common category with an average frequency of $33 \%$ is "Discuss experimental game features and payoffs" (Category 10). This category mainly includes messages that explain the value of coordination on strategy $X$ to neighbors such as "If you participate and choose $X$ you will see a much larger payoff". The category "Declare one's commitment to select Strategy X" (Category 1X) is coded with an average frequency of $28 \%$ and is often combined with Category $4 \mathrm{X}$ as is evident from the statement "I'm going to choose A. it would do well if you did the same. We will garner the most money this way". In fact 61 instances of $X$ choices are observed in the periods in which players sent messages (through 65 chat rooms) conveying their commitment to strategy $X$. Such commitment is also predicated on past behavior. Of the subjects who communicated to neighbors that they were committed to $X$ (in 44 chat rooms), 32 had chosen $X$ in the previous period. ${ }^{19}$ These findings support the self-signaling and selfcommitting conjectures Blume (1998) makes about behavior in games with one-way communication.

Finally, Category 8, denoting “Ask neighbors to influence their other neighbor's future strategy choice", has a frequency of $18 \%$. This category highlights the fact that subjects recognize the importance of the network structure in transmitting information about sustained participation and efficient coordination from one person to other in "stages" as presented in Chwe (2000). Thus, subject use

\footnotetext{
${ }^{19}$ The number of chat rooms (44) is different from the total classified in Category $1 \mathrm{X}$ (65) because when assessing the relationship between messaging content and previous period behavior, we excluded 21 chat rooms for Period 1 for which there is no past history and for Period 16 in which neighbor identity and cost treatment was changed.
} 
messages such as "The entire room needs to choose $X$ to maximize payout, begin choosing $X$ and pass it on to your other neighbor" in 39 chat rooms.

These frequently used categories represent the overarching goal of communication within this strategic setting - namely to reduce strategic uncertainty in favor of a strategy, to spread information about the benefits of choosing a particular strategy, and to generate sustained commitment for that strategy. The choice data confirm that communication is successful because relative to NO-COMM settings, very little time trend exists in participation rates (Figure 1 bottom panel) and a weak or no time trend exists for $X$ choices conditional on participation (bottom panel of Figure II in Appendix A). Thus, in this setting, an explicit costly communication stage supplements tacit communication induced through the transaction cost stage in order for strategic uncertainty to be resolved in favor of the efficient outcome.

It is to be noted that despite the obvious value of communication to promote coordination, 17 (out of 64) individuals across all COMM sessions never communicate. Many of these individuals have communicating neighbors who provide them with information about their upcoming actions and behavior in other parts of the network while the others (who have no communicating neighbors) rely on information feedback at the end of a period. An evaluation of actions of these individuals indicate that there are only 2 subjects who select $Y$ in some periods and 2 more who choose non-participation more than strategy $X$. The remaining 15 subjects pick $X$ in most periods. Thus, we can conjecture that most of these individuals rely on the high and low transaction cost payment as a form of tacit communication to resolve their own and neighbors' strategic uncertainty in favor of participation and choice of the efficient strategy rather than incurring the messaging cost in the explicit communication stage. ${ }^{20}$

To evaluate the impact of transaction costs on participation in the presence of communication opportunities, we analyze participation decisions using 2-way clustered logit regressions for both phases.

\footnotetext{
${ }^{20}$ A key element of this paper is that endogenous communication possibilities cause different subjects to have different messaging profiles; that is, some never communicate, others communicate with both neighbors while the remaining communicate with only one neighbor in a period. This is interesting because the value of every message transmitted and subsequently its role in reducing strategic uncertainty needs to be evaluated in the context of all exchanged messages (Blume and Ortmann 2007). However, in our paper we do not analyze messages and subject behavior by communication profiles, as these profiles are not exogenously imposed. We thank an anonymous referee for suggesting this as an interesting topic for future research.
} 
The dependent variable is the likelihood of participation in a period. The control variable is the dummy variable taking a value of 1 for the high cost sessions. ${ }^{21}$ The standard errors are clustered by subject and period (Cameron et al. 2012). The regression results are presented in Model (1) and Model (2) of Table 4 and suggest no significant transaction cost treatment effect in Phase I and a negative and significant effect in Phase II at 1\% significance level. This result provides partial support (in Phase II only) for Hypothesis I for the COMM treatment. Note that this result contrasts with the finding in the NO-COMM treatment, where the treatment effect is found in Phase I only.

In the COMM treatment subjects use communication to encourage their neighbors to participate, to generate commitment for choosing the efficient strategy, and to ensure that the willingness to participate and the commitment to choose $X$ is passed on to other parts of the local network through direct and indirect neighbor linkages. This implies that in Phase I communication allows groups to sustain a stable participation rate over repeated interactions even with high transaction costs. Combined with the fact that participation rates remain high and stable in the low cost groups, no treatment effect emerges in Phase I. In Phase II after the treatment switchover, participation rates remain near the level observed during Phase I in the LHTC-COMM groups. For the HLTC-COMM groups, nearly everyone participates in Phase II owing to improvement in cost conditions. This situation leads to a significant cost treatment effect in Phase II.

Conditional on participation, 2-way clustered logit regression results indicate a significantly greater likelihood (at $1 \%$ level of significance) of $X$ choices in high cost groups than in low cost groups in the presence of communication in Phase I. This provides support for Hypothesis II for the communication treatment and is contrary to the result obtained for NO-COMM. One possible explanation for this finding is that since subjects are already paying a high transaction cost, the extra communication fee if paid increases the value of the information received and focuses behavior of more subjects (senders and receivers) on choice $X$ in the HLTC-COMM sessions than it does in the LHTC-COMM sessions where the losses from paying the transaction cost and the messaging fee are lower.

\footnotetext{
${ }^{21}$ We do not control for learning effects since Figure 1 (bottom panel) does not indicate any trend in the data.
} 
Considering differences in behavior driven by the communication treatment, relative to no communication we can draw two conclusions from Figure 1. First, the participation rate is on average higher with communication than without it under both transaction cost conditions. Second, communication plays a more important role in the high transaction cost groups than in the low cost groups. Communication in high-cost groups averts the negative trend observed in the corresponding groups without communication in both phases, whereas in the low-cost groups behavior is relatively stable both with and without communication. For a statistical analysis of these claims, we employ 4 clustered logit regressions (one for each Phase and transaction cost condition). The dependent variable is again the likelihood of participation, which is regressed on a dummy variable equal to 1 for the COMM sessions, the reciprocal of the Period variable to control for learning and capture the time trends, and an interaction term between these two variables to account for differences in learning rates between treatments. All standard errors are clustered by subject and period. Table 5 presents the results in Models (1) through (4).

A positive and significant estimate (at the $1 \%$ level) is obtained for the communication treatment dummy variable in both phase regressions for the high cost condition and for Phase II of the low cost condition, providing partial support for Hypothesis III(a). The positive estimate for the reciprocal of the period variable and the negative estimate for the interaction term for both phases of the high-cost treatment and for Phase I of the low-cost treatment indicates that game experience moderates the impact of communication on participation rates. Taken together, relative to the NO-COMM setting, explicit communication although increasing the transaction costs paid has an unambiguously positive effect under unfavorable participation conditions. Prior experience with high costs improves outcomes under low cost conditions in Phase II suggesting that relative to NO-COMM settings, subjects are able to realize and upfront capitalize on communication opportunities when their participation circumstances improve. However since the messaging fee does not increase the total costs of communication by a large extent and also does not change the Nash equilibria of the $\mathrm{AB}$ game, without any previous exposure the low cost 
groups in Phase I do not experience this improvement. These groups have to rely on repeated interactions to reap the benefits of communication. To summarize:

Result 3: Communication generates greater rates of participation in the AB scheme. Communication has a greater positive impact when compared to the no-communication setting in high-cost groups at all levels of subject experience than in low-cost groups. ${ }^{22}$

\subsection{Spatial Coordination}

This section presents an analysis of location-specific land use choices of all participants to assess the performance of the $\mathrm{AB}$ in creating spatially coordinated land use patterns. We develop a performance metric counting every instance where a subject and his/her two direct neighbors within their local neighborhood are able to locally coordinate on the same land use strategy. This metric can take a maximum value of 8 , signifying that all 8 group members are perfectly or globally coordinated on either strategy $X$ or $Y$. Any other lower non-zero value indicates only localized clustering of similar choices on the network. In this format, the same metric captures instances of both local and global coordination that are routinely observed in all groups during the experiment.

Let us start by examining spatial coordination under the no-communication regime. The top two panels of Figure 4 present the average levels of localized coordination on $X$ by a subject and both of their neighbors (termed locally efficient coordination) in the NO-COMM groups for all periods of Phases I and II. This outcome is of special interest for the high-cost condition since the non-participation strategy NP strictly dominates option $Y$. For these groups, post-participation, forward induction reasoning can guide many adjacent subjects' choices to the Pareto efficient $X$ equilibrium. While forward induction may not

\footnotetext{
${ }^{22}$ In the sessions where messaging was free, observed participation and efficient choices were very near $100 \%$. This outcome reiterates the observation that while communication does not eliminate any of the Nash equilibria of the game, the ability to send messages can make the efficient Nash equilibrium a focal point (thus reducing game strategic uncertainty) and can lead to greater rates of efficient play for both senders and receivers (Farrell 1987). In that sense the presence of the free communication and transaction cost induced tacit communication reinforces the focal nature of the efficient equilibrium leading to near perfect efficient coordination.
} 
explain the many adjacent $X$ choices in the low-cost groups, the transaction cost serves as a costly tacitcommunication mechanism and focuses multiple neighbors' choices on $X$, which pays more than $Y$ in the event of localized coordination.

A Wilcoxon Mann-Whitney test detects a significant difference in efficient localized coordination between low and high-cost groups without communication $(p$-value $=0.05)$ in Phase I after Period 8 . This finding is aligned with the results supporting Hypothesis I as discussed previously. Since participation is significantly lower in the HLTC-NO-COMM sessions, so is overall AB performance. A reason for any significant difference appearing only after Period 8 is that in the initial periods subjects are unfamiliar with the strategic environment, so most $X$ choices are either non-adjacent or are by two neighbors (which is not recorded by the performance metric).

With repeated interactions, participation rates fall in both groups, but they fall more steeply in the high-cost sessions (as an increasing number of subjects' strategic uncertainty gets resolved in favor of $N P$ ) causing fewer neighbors to choose $X$. As a result, rates of localized efficient coordination fall to about $14 \%$ in Period 15 in HLTC-NO-COMM groups. Performance is maintained between $40 \%$ and $50 \%$ in the LHTC-NO-COMM groups, where more people choose $X$ and the participation rate has a weak negative trend, leading to the significant treatment effect. In Phase II there is no significant difference across transaction cost treatments, consistent with the previous result regarding no significant difference in participation rates.

Figure 5 presents the fraction of instances of globalized efficient coordination pooled across all NO-COMM sessions. Wilcoxon Mann-Whitney tests indicate no significant cost-treatment effect in either Phase. Group-level coordination is difficult - for any value of the transaction cost, it is challenging to get all group members to make the same choices, especially given that information feedback is limited to direct neighbors. Yet positive rates of global coordination suggest that, despite participation challenges, the $\mathrm{AB}$ scheme can sometimes fully coordinate environmentally-beneficial choices. 
Result 4: With no explicit communication opportunities, greater transaction costs reduce localized efficient coordination only for inexperienced groups. Globalized efficient coordination is not significantly impacted by variation in the transaction cost values.

Let us now compare rates of spatial coordination with communication. The bottom panel of Figure 4 shows the percentage of localized coordination in the COMM groups by transaction cost for both phases. A surprising result is that in Phase I, localized coordination is greater in the HLTC-COMM groups relative to the LHTC-COMM groups. This difference is marginally significant at the $10 \%$ level on the basis of a 2-way clustered logit regression (Table 4, Model (3)) where the dependent variable takes a value of one when players within a local neighborhood are able to coordinate on the efficient strategy $X$ and 0 otherwise. The independent variables are the high cost treatment dummy and the reciprocal of the period variable included to capture non-linear rates of learning. Thus, although in Phase I there is no support for Hypothesis I (as there is no difference in the number of individuals who participate under the two cost conditions with communication), more neighboring players participate in HLTC-COMM groups than in LHTC-COMM groups. Localized coordination is improved in low-cost groups in Phase II relative to high-cost groups since virtually every individual in the HLTC-COMM group participates (reinforcing the significant treatment effect supporting Hypothesis I) and nearly everyone chooses $X$. Model (4) in Table 4 shows that this difference is statistically significant at the $1 \%$ level on the basis of a 2 -way clustered logit regression. ${ }^{23}$

Finally, we compare localized coordination rates with and without communication. Models (5) through (8) in Table 5 present the results of four 2-way clustered logit regressions (for each Phase and transaction cost condition). The dependent variable takes a value of one when players within a local neighborhood are able to coordinate and choose $X$. Similar to the previous models, the control variables include a dummy variable taking a value of 1 for the COMM sessions, the reciprocal of the period

\footnotetext{
${ }^{23} 2$-way clustered logit regressions (with every group being the unit of observation) indicate no significant effect of transaction costs on likelihood of global efficient coordination in the presence of communication.
} 
variable and an interaction term. Results indicate a significant (at the $1 \%$ level) and positive estimate for the COMM dummy variable in both phase regressions for the high transaction cost condition and for the low cost condition in Phase II, substantiating the information presented in Figure 4 when comparing across top and bottom panels for each cost condition and phase.

Relative to the baseline settings where the high and low transaction costs present opportunities for tacit communication, explicit messaging can guide behavior of a greater number of adjacent individuals to the efficient choice, significantly improving the likelihood of localized efficient coordination. For groups facing low transaction costs, the COMM dummy variable is not significant in Phase I which is in line with Result 3. Moreover, the signs of the significant estimates for the interaction term and the reciprocal of the period variable for the high cost models indicate that with communication repeated interactions improves performance. Again, effect of communication in low cost groups is only obtained in Phase II, similar to Result 3. The regression results partially support Hypothesis III(b) and underscore the positive role of explicit communication in promoting efficient Nash equilibrium selection in coordination games with both Pareto-dominant and risk-dominant Nash equilibria within a local network.

Result 5: Explicit communication opportunities lead to significantly improved AB performance relative to baseline situations where communication is tacit. This effect is true for all levels of game experience when groups face high transaction costs. For low cost groups, the beneficial effect of communication is contingent on whether they faced high costs in the past. 


\section{Discussion}

Our study results are of course predicated on the nature of the strategic environment, i.e., the payoff functions under either high or low transaction costs, the size and circular nature of the local network, and the degree of information feedback. A circular network does not describe many real world settings where an $\mathrm{AB}$ policy could be introduced. Using a spatial set-up different from the circular network (such as a line or lattice) may produce different results, since some individuals will have different numbers of neighbors, and will therefore face different levels of strategic uncertainty and payoffs. In the context of coordination games, Cassar (2007) finds that the frequency of payoff-dominant choices is higher in a "small world" or a "random" network than in a local network such as the one we consider. She also finds that coordination is obtained much faster in the small world setting, while noting that "a theory linking network characteristics to individual behavior is not yet available" (page 228). However, compared to networks where strategic uncertainty varies across players, we could argue that the circular network provides a lower bound on coordination failure in an AB setting.

We could have chosen a transaction cost value less than 40, which would not have made $Y$ strictly dominated by $N P$. We conjecture that this would lead to much greater participation and many more $Y$ choices than is currently observed under the high-cost treatment. While this is interesting, this finding is similar to results obtained in Banerjee et al. (2014) and could have eliminated (i) any difference between high-cost and low-cost groups and (ii) subjects' ability to use forward induction to guide their behavior in our network $\mathrm{AB}$ coordination game. Moreover, the transaction cost treatment is more interesting if it generates differences in the set of equilibria compared to when it just produces a difference in net payoffs. This leads to an interesting thought experiment: if a regulator wishes to increase participation or efficient localized coordination in an $\mathrm{AB}$ scheme for a given budget, is it better to spend this money on increasing the baseline (participation) subsidy, or on subsidizing the transactions costs that participants face (e.g. by providing free advice)? In our experiment, no real difference exists in the effects of these actions if the subsidy increase is equivalent for schemes $X$ and $Y$, other than in the framing of the payments. But targeting the baseline subsidy increase at $X$ only could increase the uptake of this land use relative to $Y$ or 
non-participation by more than an equivalent reduction in transactions costs. Unfortunately, we were unable to test whether significant differences in desired spatial coordination emerge from such reallocation of funds in the lab.

The size of the circular network and nature of information feedback may also impact behavior. More information and smaller group sizes usually generate greater rates of efficient choices in coordination games. However, with a group size of 8 we believe we have struck a reasonable middle ground whereby the group is small enough for many individuals to choose $X$ and large enough for many to select $N P$ or $Y$ (owing to high strategic uncertainty). With this group size we are able to assess the extent to which the $\mathrm{AB}$ can still deliver on its environmental goal when the effect of each individual is relatively small compared to the total group. Finally, we could have provided information to subjects beyond their local neighborhoods (e.g., on their indirect neighbors such as in Banerjee et al., 2014). Although this would be inconsistent with our localized communication format, it provides an avenue for future research especially if regulatory agencies start publicly announcing enrollment rates in order to promote greater participation. It is also possible that coordination failure would have implications for what participants consider "fair", and this could influence the likelihood of coordination on the Paretosuperior equilibrium, especially if outcomes are observable such as in Reeson et al. (2011).

\section{Conclusions}

PES schemes are increasingly being implemented as policy mechanisms to enhance the supply of ecosystem services. The predominant property rights regime in countries such as the US, the UK, New Zealand and Australia requires that producers be financially compensated to encourage the supply of ecosystem services, rather than being compelled to do so by regulation: the "provider gets" principle (Hanley et al., 1998). Second, for many environmental outcomes, spatial coordination increases the size of environmental benefits for a given level of enrollment in voluntary conservation programs. The policy design challenge is to find systems of incentives that spatially coordinate a voluntary sign-up program. The Agglomeration Bonus $(\mathrm{AB})$ is one such mechanism. However, the $\mathrm{AB}$ faces a number of potential 
problems, including the tendency over time for participants to converge on risk-dominant outcomes, a lack of cost-effectiveness, and, like many incentive programs, the size and nature of transaction costs. To date, the effects of transactions costs have not been investigated in the $\mathrm{AB}$ literature, despite their importance to PES scheme participation decisions.

In this paper we use a laboratory experiment to investigate how private transaction costs affect the degree of participation in an $\mathrm{AB}$ scheme, its efficiency and the patterns of spatial coordination in the presence and absence of communication. We also show how these results are moderated by the availability of unstructured (and rich) communication opportunities with direct and indirect neighbors an issue not widely explored in the $\mathrm{AB}$ game literature. Results show that higher transaction costs lead to greater non-participation even though they have the potential to serve as a means of tacit communication to facilitate coordination on the efficient equilibrium. Lower transaction costs on the other hand are conducive to producing a greater degree of coordination on the most preferred environmental outcome even though they serve as a weaker form of tacit communication. Full coordination on the most efficient outcome is rarely achieved, but localized clusters of coordinated conservation actions emerge in most cases.

Explicit communication is costly and adds to the transaction costs incurred, but it improves outcomes largely because it can reduce the strategic uncertainty associated with participation and coordination in the $\mathrm{AB}$ scheme. There are clear parallels here with experimental findings on the implications of communication (albeit costless) in "ambient" pollution tax schemes (Segerson, 1988), where the pollution tax liability of each firm depends on group behavior. For example, Suter et al. (2008) find that allowing participants to communicate in a non-binding fashion produces lower pollution levels and maximizes group profits. Our communication results can also be compared with the effects of costless communication in experiments on Voluntary Contribution Mechanisms for public goods, such as in Isaac and Walker (1988), where nonbinding group discussion significantly reduced free-riding behavior. 
The policy implications of our results are clear: if the regulator can design an $\mathrm{AB}$ scheme in a way which keeps transaction costs low relative to the payoffs of coordination, then it will be easier to achieve spatial coordination (both locally and globally). This, in turn, enhances a more effective delivery of ecosystem services. However, if achieving a given environmental objective requires writing (complicated) rules for potential participants, then there is a trade-off between improving environmental effectiveness and increasing coordination, since such complications will increase transactions costs. Set against this scenario, facilitating low-cost communication between producers would improve the likelihood of successful coordination towards socially-desirable land use patterns. Providing subsidies to lower transaction costs during the initial phases of a PES program would also foster coordination, and our results suggest that improved performance could persist even after such subsidies are removed and transaction costs increase. 


\section{References}

Armsworth, Paul R., Szvetlana Acs, Martin Dallimer, Kevin J. Gaston, Nick Hanley, and Paul Wilson. 2012. The cost of policy simplification in conservation incentive programs. Ecology Letters 15 (5): 406-14.

Banerjee, Simanti, Nick Hanley, Frans P. deVries, and Daan P. van Soest. 2014. The impact of information provision on agglomeration bonus performance: An experimental study on local networks. American Journal of Agricultural Economics 96 (4): 1009-29.

Banerjee, Simanti, Anthony M. Kwasnica, and James S. Shortle. 2012. Agglomeration bonus in small and large local networks: A laboratory examination of spatial coordination. Ecological Economics 84 (0) (12): $142-52$.

Berninghaus, Siegfried K., Karl-Martin Ehrhart, and Claudia Keser. 2002. Conventions and local interaction structures: Experimental evidence. Games and Economic Behavior 39 (2): 177-205.

Blume, Andreas. 1998. Communication, risk, and efficiency in games. Games and Economic Behavior 22 (2) (February 1998): 171-202.

Blume, Andreas, and Andreas Ortmann. 2007. The effects of costless pre-play communication: Experimental evidence from games with pareto-ranked equilibria. Journal of Economic Theory 132 (1) (1): 274-90.

Cachon, Gérard P., and Colin F. Camerer. 1996. Loss-avoidance and forward induction in experimental coordination games. The Quarterly Journal of Economics 111 (1) (Feb.): 165-94.

Cameron, A. Colin, Jonah B. Gelbach, and Douglas L. Miller. 2012. Robust inference with multiway clustering. Journal of Business \& Economic Statistics 29 (2): 238-49.

Cason, Timothy N., and Leigh Raymond. 2011. Framing effects in an emissions trading experiment with voluntary compliance. In Experiments on energy, the environment, and sustainability (research in experimental economics, volume 14), eds. R. Mark Isaac, Douglas A. Norton, 77-114Emerald Group Publishing Limited.

Cassar, Alessandra. 2007. Coordination and cooperation in local, random and small world networks: Experimental evidence. Games and Economic Behavior 58 (2) (2): 209-30.

Charness, Gary. 2000. Self-serving cheap talk: A test of Aumann's conjecture. Games and Economic Behavior 33 (2) (November 2000): 177-94.

Chwe, Michael Suk-Young. 2000. Communication and coordination in social networks. The Review of Economic Studies 67 (1): 1-16.

Clark, Kenneth, Stephen Kay, and Martin Sefton. 2001. When are Nash equilibria self-enforcing? An experimental analysis. International Journal of Game Theory 29 (4): 495-515. 
Claassen, Roger, and Marc Ribaudo. 2016. Cost-effective conservation programs for sustaining environmental quality. Choices 31 (3).

Cohen, Jacob. 1960. A coefficient of agreement for nominal scales. Educational and Psychological Measurement 20: 37-46.

Conservation Stewardship Program, Natural Resources Conservation Service, 2016. http://www.nrcs.usda.gov/wps/portal/ $/$ main/national/programs/financial/csp/ Accessed July 27, 2016

Cooper, Russell, Douglas V. DeJong, Robert Forsythe, and Thomas W. Ross. 1989. Communication in the battle of the sexes game: Some experimental results. The Rand Journal of Economics 20 (4) (Winter): 568-87.

Cooper, Russell, Douglas V. DeJong, Robert Forsythe, and Thomas W. Ross. 1992. Communication in coordination games. The Quarterly Journal of Economics 107 (2) (May): 739-71.

Cooper, Russell, Douglas V. DeJong, Robert Forsythe, and Thomas W. Ross. 1994. Alternative institutions for resolving coordination problems: Experimental evidence on forward induction and pre-play communication. In Problems of coordination in economic activity, ed. James Friedman, 129-146. New York: Springer.

Cooper, Tamsin, Kaley Hart, and David Baldock. 2009. "Provision of public goods through agriculture in the European Union". Institute for European Environmental Policy London.

Dallimer, M., K. J. Gaston, A. M. Skinner, N. Hanley, S. Acs, and P. R. Armsworth. 2010. Field-level bird abundances are enhanced by landscape-scale agri-environment scheme uptake. Biology Letters 6 (5) (Oct 23): 643-6.

Devetag, Giovanna. 2003. Coordination and information in critical mass games: An experimental study. Experimental Economics 6 (1): 53-73.

Duffy, John, and Nick Feltovich. 2002. Do actions speak louder than words? An experimental comparison of observation and cheap talk. Games and Economic Behavior 39 (1): 1-27.

Dufwenberg, Martin, Gunnar Köhlin, Peter Martinsson, and Haileselassie Medhin. 2016. Thanks but no thanks: A new policy to reduce land conflict. Journal of Environmental Economics and Management 77 (1): 31-50.

Engel, Stefanie, Stefano Pagiola, and Sven Wunder. 2008. Designing payments for environmental services in theory and practice: An overview of the issues. Ecological Economics 65 (4) (5/1): 66374.

Falconer, Katherine, and Caroline Saunders. 2002. Transaction costs for SSSIs and policy design. Land use Policy 19 (2): 157-66.

Farrell, Joseph. 1987. Cheap talk, coordination, and entry. The Rand Journal of Economics: 34-9. 
Fischbacher, Urs. 2007. Z-tree: Zurich toolbox for ready-made economic experiments. Experimental Economics 10: 171.

Fooks, Jacob R., Nathaniel Higgins, Kent D. Messer, Joshua M. Duke, Daniel Hellerstein, and Lori Lynch. 2016. Conserving spatially explicit benefits in ecosystem service markets: Experimental tests of network bonuses and spatial targeting. American Journal of Agricultural Economics 98 (2): 46888 .

Greiner, Ben. 2015. Subject pool recruitment procedures: Organizing experiments with ORSEE. Journal of the Economic Science Association 1 (1): 114-25.

Hanley, Nick, Simanti Banerjee, Gareth D. Lennox, and Paul R. Armsworth. 2012. How should we incentivize private landowners to 'produce' more biodiversity? Oxford Review of Economic Policy 28 (1): 93-113.

Hanley, Nick, Hilary Kirkpatrick, Ian Simpson, and David Oglethorpe. 1998. Principles for the provision of public goods from agriculture: Modeling moorland conservation in Scotland. Land Economics: 102-13.

Hanley, Nick, and Ben White. 2014. Incentivizing the provision of ecosystem services. International Review of Environmental and Resource Economics 7 (3-4): 299-331.

Harsanyi, John C., and Reinhard Selten. 1988. A general theory of equilibrium selection in games. MIT Press Books 1.

Heinemann, Frank, Rosemarie Nagel, and Peter Ockenfels. 2009. Measuring strategic uncertainty in coordination games. The Review of Economic Studies 76 (1): 181-221.

Hurkens, Sjaak. 1996. Multi-sided pre-play communication by burning money. Journal of Economic Theory 69 (1) (April 1996): 186-97.

Isaac, R. Mark, and James M. Walker. 1988. Communication and free-riding behavior: The voluntary contribution mechanism. Economic Inquiry 26 (4): 585-608.

Jackson, Matthew O. 2010. Social and economic networks. Vol. 3. Princeton: Princeton University Press.

Kampas, Athanasios, and Ben White. 2004. Administrative costs and instrument choice for stochastic non-point source pollutants. Environmental and Resource Economics 27 (2): 109-33.

Krippendorff, Klaus. 2004. Content analysis: An introduction to its methodology. Sage.

Kuhfuss, Laure, Raphaële Préget, Sophie Thoyer, and Nick Hanley. 2016. Nudging farmers to enroll land into agri-environmental schemes: The role of a collective bonus. European Review of Agricultural Economics 43 (4): 609-36.

Landis, J. Richard, and Gary G. Koch. 1977. An application of hierarchical kappa-type statistics in the assessment of majority agreement among multiple observers. Biometrics: 363-74. 
Lane, SN, CJ Brookes, MJ Kirkby, and J. Holden. 2004. A network- index- based version of TOPMODEL for use with high- resolution digital topographic data. Hydrological Processes 18 (1): 191-201.

Lane, Stuart N., Chris J. Brookes, A. Louise Heathwaite, and Sim Reaney. 2006. Surveillant science: Challenges for the management of rural environments emerging from the new generation diffuse pollution models. Journal of Agricultural Economics 57 (2): 239-57.

Lawley, Chad, and Wanhong Yang. 2015. Spatial interactions in habitat conservation: Evidence from prairie pothole easements. Journal of Environmental Economics and Management 71 (5): 71-89.

McCann, Laura, Bonnie Colby, K. William Easter, Alexander Kasterine, and K. V. Kuperan. 2005. Transaction cost measurement for evaluating environmental policies. Ecological Economics 52 (4) (3/1): 527-42.

Merckx, Thomas, Ruth E. Feber, Philip Riordan, Martin C. Townsend, Nigel A. D. Bourn, Mark S. Parsons, and David W. Macdonald. 2009. Optimizing the biodiversity gain from agri-environment schemes. Agriculture, Ecosystems \& Environment 130 (3-4) (4): 177-82.

Mettepenningen, Evy, Ann Verspecht, and Guido Van Huylenbroeck. 2009. Measuring private transaction costs of european agri-environmental schemes. Journal of Environmental Planning and Management 52 (5): 649-67.

Önal, Hayri, and Robert A. Briers. 2006. Optimal selection of a connected reserve network. Operations Research 54 (2): 379-88.

Parkhurst, Gregory M., and Jason F. Shogren. 2007. Spatial incentives to coordinate contiguous habitat. Ecological Economics 64 (2): 344-55.

Parkhurst, Gregory M., Jason F. Shogren, Chris Bastian, Paul Kivi, Jennifer Donner, and Rodney BW Smith. 2002. Agglomeration bonus: An incentive mechanism to reunite fragmented habitat for biodiversity conservation. Ecological Economics 41 (2): 305-28.

Plott, Charles R., and Dean V. Williamson. 2000. Markets for contracts: Experiments exploring the compatibility of games and markets for games. Economic Theory 16 (3) (Nov.): 639-60.

Reeson, Andrew F., Luis C. Rodriguez, Stuart M. Whitten, Kristen Williams, Karel Nolles, Jill Windle, and John Rolfe. 2011. Adapting auctions for the provision of ecosystem services at the landscape scale. Ecological Economics 70 (9) (7/15): 1621-7.

Romero, Julian. 2015. The effect of hysteresis on equilibrium selection in coordination games. Journal of Economic Behavior \& Organization 111 (0) (3): 88-105.

Segerson, Kathleen. 1988. Uncertainty and incentives for nonpoint pollution control. Journal of Environmental Economics and Management 15 (1): 87-98.

Shortle, James S., David G. Abler, and Richard D. Horan. 1998. Research issues in nonpoint pollution control. Environmental and Resource Economics 11 (3-4): 571-85. 
Shortle, James S., Marc Ribaudo, Richard D. Horan, and David Blandford. 2012. Reforming agricultural nonpoint pollution policy in an increasingly budget-constrained environment. Environmental Science \& Technology 46 (3): 1316-25.

Suter, Jordan F., Christian A. Vossler, Gregory L. Poe, and Kathleen Segerson. 2008. Experiments on damage-based ambient taxes for nonpoint source polluters. American Journal of Agricultural Economics 90 (1): 86-102.

Van Huyck, John B., Raymond C. Battalio, and Richard O. Beil. 1990. Tacit coordination games, strategic uncertainty, and coordination failure. The American Economic Review 80 (1): 234-248.

Van Huyck, John B., Raymond C. Battalio, and Richard O. Beil. 1991. Strategic uncertainty, equilibrium selection, and coordination failure in average opinion games. The Quarterly Journal of Economics 106 (3): 885-910.

Van Huyck, John B., Raymond C. Battalio, and Richard O. Beil. 1993. Asset markets as an equilibrium selection mechanism: Coordination failure, game form auctions, and tacit communication. Games and Economic Behavior5 (3) (7): 485-504.

Warziniack, Travis, Jason F. Shogren, and Gregory Parkhurst. 2007. Creating contiguous forest habitat: An experimental examination on incentives and communication. Journal of Forest Economics 13 (2): 191-207.

Wätzold, Frank, Melanie Mewes, Rob van Apeldoorn, Riku Varjopuro, Tadeusz Jan Chmielewski, Frank Veeneklaas, and Marja-Leena Kosola. 2010. Cost-effectiveness of managing natura 2000 sites: An exploratory study for finland, germany, the netherlands and poland. Biodiversity and Conservation 19 (7): 2053-69.

Williams, Justin C., Charles S. ReVelle, and Simon A. Levin. 2005. Spatial attributes and reserve design models: A review. Environmental Modeling \& Assessment 10 (3): 163-81.

Windle, Jill, John Rolfe, Juliana McCosker, and Andrea Lingard. 2009. A conservation auction for landscape linkage in the southern desert uplands, queensland. The Rangeland Journal 31 (1): 12735 .

Wunder, Sven. 2007. The efficiency of payments for environmental services in tropical conservation; la eficiencia de los pagos por servicios ambientales en la conservación trópicos. Conservation Biology 21 (1): 48-58. 


\section{TABLES}

Table 1a: Payoff Table for High Transaction Cost condition

Actions Chosen by Neighbors

\begin{tabular}{ccccccc}
\hline Your Action & $\begin{array}{c}\text { Both } \\
\text { Participate } \\
\text { Choose X }\end{array}$ & $\begin{array}{c}\text { Both } \\
\text { Participate } \\
\text { and one } \\
\text { Chooses X } \\
\text { other Y }\end{array}$ & $\begin{array}{c}\text { Both } \\
\text { Participate } \\
\text { and Choose }\end{array}$ & $\begin{array}{c}\text { Only one } \\
\text { Participates } \\
\text { \& Chooses X }\end{array}$ & $\begin{array}{c}\text { Only one } \\
\text { Participates } \\
\text { \& Chooses Y }\end{array}$ & $\begin{array}{c}\text { No Neighbor } \\
\text { Participates }\end{array}$ \\
\hline X & 210 & 125 & 40 & 125 & 40 & 40 \\
Y & 145 & 155 & 165 & 145 & 155 & 145 \\
$\begin{array}{c}\text { NP (Non- } \\
\text { Participation) }\end{array}$ & 175 & 175 & 175 & 175 & 175 & 175 \\
\hline
\end{tabular}

Table 1b: Payoff Table for Low Transaction Cost condition

Actions Chosen by Neighbors

\begin{tabular}{ccccccc}
\hline Your Action & $\begin{array}{c}\text { Both } \\
\text { Participate } \\
\text { Choose X }\end{array}$ & $\begin{array}{c}\text { Participate } \\
\text { \& one } \\
\text { Chooses X } \\
\text { \& other Y }\end{array}$ & $\begin{array}{c}\text { Both } \\
\text { Participate } \\
\text { \& Choose }\end{array}$ & $\begin{array}{c}\text { Y } \\
\text { Only one } \\
\text { Participates } \\
\text { \& Chooses X }\end{array}$ & $\begin{array}{c}\text { Only one } \\
\text { Participates } \\
\text { \& Chooses Y }\end{array}$ & $\begin{array}{c}\text { No } \\
\text { Neighbor } \\
\text { Participates }\end{array}$ \\
\hline X & 235 & 150 & 65 & 150 & 65 & 65 \\
Y & 170 & 180 & 190 & 170 & 180 & 170 \\
NP (Non- & 175 & 175 & 175 & 175 & 175 & 175 \\
Participation) & & & & & & \\
\hline
\end{tabular}

Table 2: Summary of Experimental Design

\section{Communication Treatment}

\begin{tabular}{ccc}
\hline Transaction Cost Ordering Treatment & No-Comm & Comm \\
\hline High-Low & HLTC-No-Comm & HLTC-Comm \\
Low-High & ( $\begin{array}{c}\text { sessions }) \\
\text { LHTC-No-Comm } \\
\text { (8 sessions })\end{array}$ & LHTC-Comm \\
& $(4$ sessions $)$ \\
\hline
\end{tabular}


Table 3: Categories for coding messages (reaching at least Moderate Reliability) and observed frequency in chat rooms

\begin{tabular}{|c|c|c|c|}
\hline Category $^{+}$ & Description & $\begin{array}{l}\text { Cohen's } \\
\text { Kappa }\end{array}$ & $\begin{array}{l}\text { Relative } \\
\text { Frequency } \\
\text { of Coding }\end{array}$ \\
\hline 1 & Declare one's commitment to a particular strategy & & \\
\hline $1 \mathrm{X}$ & Will select $X$ & 0.83 & $0.28 *$ \\
\hline $1 \mathrm{Y}$ & Will select $Y$ & 0.90 & 0.03 \\
\hline $1 \mathrm{NP}$ & Will select $N P$ & 0.75 & 0.06 \\
\hline 2 & Explain own reason for choosing a strategy $(X, Y$ or $N P)$ & & \\
\hline $2 \mathrm{P}$ & In the past periods & 0.45 & 0.02 \\
\hline 3 & $\begin{array}{l}\text { Inform one neighbor about other neighbor's strategy } \\
\text { choice }\end{array}$ & & \\
\hline $3 \mathrm{X}$ & Other neighbor chose $X$ & 0.45 & 0.03 \\
\hline $3 \mathrm{Y}$ & Other neighbor chose $Y$ & 0.79 & 0.03 \\
\hline $3 \mathrm{NP}$ & Other neighbor chose NP & 0.69 & 0.04 \\
\hline $3 N X$ & Other neighbor did not chose $X$ & 0.56 & 0.03 \\
\hline 4 & Influence neighbor(s) to select a particular strategy & & \\
\hline $4 \mathrm{X}$ & Choose X & 0.81 & $0.44 *$ \\
\hline $4 \mathrm{Y}$ & Choose $Y$ & 0.78 & 0.02 \\
\hline 4NP & Choose NP & 0.79 & 0.01 \\
\hline 5 & Ask neighbors about their future choices & 0.55 & 0.07 \\
\hline 6 & Ask neighbors about their reasons for choosing a strategy & 0.65 & 0.03 \\
\hline 7 & Ask neighbors about their other neighbors past choices & 0.53 & 0.02 \\
\hline 8 & $\begin{array}{l}\text { Ask neighbors to influence their other neighbor's future } \\
\text { strategy choice }\end{array}$ & 0.88 & $0.18 *$ \\
\hline $8 \mathrm{X}$ & Influence other neighbor to select $X$ & 0.89 & 0.17 \\
\hline $8 Y$ & Influence other neighbor to select $Y$ & 0.49 & 0.00 \\
\hline 9 & Refer to own past strategy choice & 0.49 & 0.01 \\
\hline 10 & Discuss about experimental features \& game payoffs & 0.73 & $0.33 *$ \\
\hline 11 & Agree on a strategy & 0.55 & 0.13 \\
\hline 12 & Other & 0.54 & $0.34 *$ \\
\hline
\end{tabular}

${ }^{+}$Only those categories (and sub-categories) reaching an agreement of Moderate or higher reliability are listed. $X$ and $Y$ labels correspond to Strategies $A$ and $B$ in the experiment.

* Represents categories which have a relative frequency of coding of $15 \%$ or more. 
Table 4: 2-way Clustered Logit Regressions for Participation and Performance Analysis in each Phase for Communication Groups

\begin{tabular}{ccccc}
\hline $\begin{array}{c}\text { Dependent } \\
\text { Variables }\end{array}$ & \multicolumn{2}{c}{ Participation } & \multicolumn{2}{c}{ Localized Efficient Coordination } \\
\hline $\begin{array}{c}\text { Independent } \\
\text { Variables }\end{array}$ & Model 1 & Model 2 & Model 3 & Model 4 \\
\cline { 2 - 5 } & Phase I & Phase II & Phase I & Phase II \\
\hline $\begin{array}{c}\text { High Transaction } \\
\text { Cost }\end{array}$ & -0.024 & $-0.157^{* *}$ & $0.027^{*}$ & $-0.106^{* * *}$ \\
\hline $\mathbf{1}$ & $(0.019)$ & $(0.032)$ & $(0.015)$ & $(0.023)$ \\
\hline Period $^{+}$ & - & - & $-1.343^{* *}$ & $-0.756^{* *}$ \\
Constant & $2.161^{* *}$ & & $(0.344)$ & $(0.048)$ \\
\hline $\begin{array}{c}\text { Number of } \\
\text { observations }\end{array}$ & $(0.612)$ & $7.43^{* *}$ & -0.098 & $1.975^{* * *}$ \\
\hline
\end{tabular}

Cluster Variables

Individual Subject and Experimental Period in a Phase

** Represents statistical significance at the $1 \%$ level, * at the $10 \%$ level

+ Period takes a value between 1 and 15

Table 5: 2-way Clustered Logit Regressions for Performance comparison of Communication and No Communication Treatments by Phase and Transaction Cost ${ }^{\#}$

\begin{tabular}{|c|c|c|c|c|c|c|c|c|}
\hline \multirow[b]{2}{*}{$\begin{array}{l}\text { Independent } \\
\text { Variables }\end{array}$} & \multicolumn{4}{|c|}{ Participation } & \multicolumn{4}{|c|}{ Localized Efficient Coordination } \\
\hline & $\begin{array}{c}\text { Model 1: } \\
\text { Phase I } \\
(\text { HC) } \\
\end{array}$ & $\begin{array}{c}\text { Model 2: } \\
\text { Phase II } \\
\text { (LC) }\end{array}$ & $\begin{array}{c}\text { Model 3: } \\
\text { Phase I } \\
\text { (LC) } \\
\end{array}$ & $\begin{array}{c}\text { Model 4: } \\
\text { Phase II } \\
\text { (HC) }\end{array}$ & $\begin{array}{c}\text { Model 5: } \\
\text { Phase I } \\
\text { (HC) }\end{array}$ & $\begin{array}{c}\text { Model 6: } \\
\text { Phase II } \\
\text { (LC) }\end{array}$ & $\begin{array}{c}\text { Model 7: } \\
\text { Phase I } \\
\text { (LC) } \\
\end{array}$ & $\begin{array}{c}\text { Model 8: } \\
\text { Phase II } \\
\text { (HC) }\end{array}$ \\
\hline Comm & $\begin{array}{c}0.892 * * * \\
(0.229)\end{array}$ & $\begin{array}{c}1.999 * * * \\
(0.622)\end{array}$ & $\begin{array}{c}0.197 \\
(0.245)\end{array}$ & $\begin{array}{c}0.782 * * * \\
(0.246)\end{array}$ & $\begin{array}{c}1.063 * * * \\
(0.221)\end{array}$ & $\begin{array}{c}2.019 * * * \\
(0.374)\end{array}$ & $\begin{array}{c}0.028 \\
(0.192)\end{array}$ & $\begin{array}{c}0.864 * * * \\
(0.237)\end{array}$ \\
\hline$\frac{1}{\text { Period }^{+}}$ & $\begin{array}{c}2.197 * * \\
(0.871)\end{array}$ & $\begin{array}{c}0.428 \\
(0.421)\end{array}$ & $\begin{array}{c}1.960 * * * \\
(0.652)\end{array}$ & $\begin{array}{c}2.674 * * * \\
(0.902)\end{array}$ & $\begin{array}{c}0.027 \\
(0.458)\end{array}$ & $\begin{array}{l}-0.368 \\
(0.227)\end{array}$ & $\begin{array}{c}-1.152 * * * \\
(0.381)\end{array}$ & $\begin{array}{c}0.610 * * \\
(0.252)\end{array}$ \\
\hline 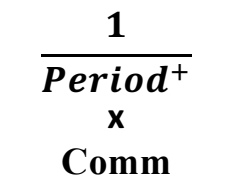 & $\begin{array}{c}-1.060 * * \\
(-0.467)\end{array}$ & $\begin{array}{r}-1.094 \\
(0.81)\end{array}$ & $\begin{array}{c}-1.285^{* * *} \\
(0.356)\end{array}$ & $\begin{array}{c}- \\
1.179 * * * \\
(0.489)\end{array}$ & $\begin{array}{c}-0.848 * * \\
(0.368)\end{array}$ & $\begin{array}{l}-0.375 \\
(0.658)\end{array}$ & $\begin{array}{c}0.078 \\
(0.327)\end{array}$ & $\begin{array}{c}-0.652 * * * \\
(0.095)\end{array}$ \\
\hline Constant & $\begin{array}{c}-0.600 * * \\
(0.29)\end{array}$ & $\begin{array}{c}1.579 * * * \\
(0.251)\end{array}$ & $\begin{array}{c}1.549 * * * \\
(0.29)\end{array}$ & $\begin{array}{l}-0.5^{*} \\
(0.26)\end{array}$ & $\begin{array}{c}-1.088 * * * \\
(0.297)\end{array}$ & $\begin{array}{l}-0.086 \\
(0.728)\end{array}$ & $\begin{array}{c}0.171 \\
(0.449)\end{array}$ & $\begin{array}{c}-0.546^{* *} \\
(0.245)\end{array}$ \\
\hline $\begin{array}{c}\text { Number of } \\
\text { Observations }\end{array}$ & \multicolumn{8}{|c|}{1440} \\
\hline $\begin{array}{c}\text { Cluster } \\
\text { Variables }\end{array}$ & \multicolumn{8}{|c|}{ Individual Subject and Experimental Period in a Phase } \\
\hline
\end{tabular}




\section{FIGURES}

No-Comm, Phase

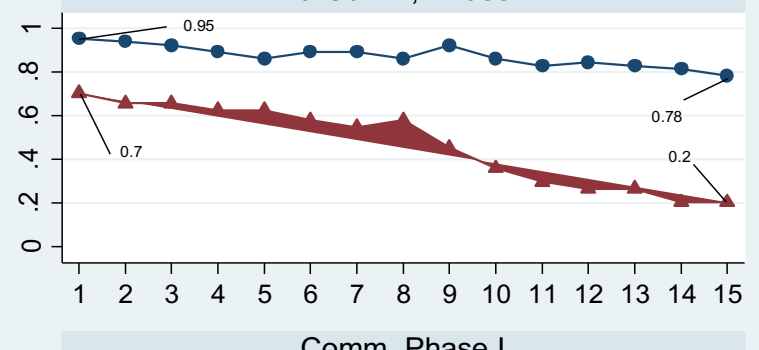

Comm, Phase I

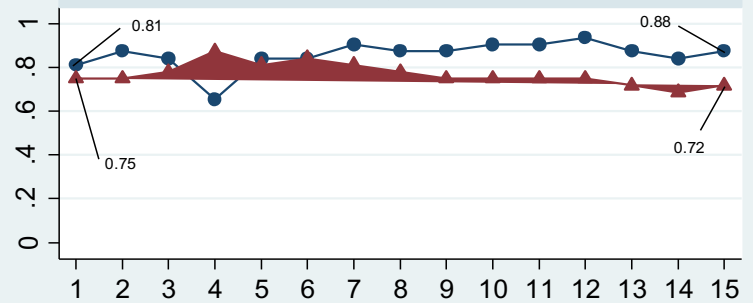

No-Comm, Phase II

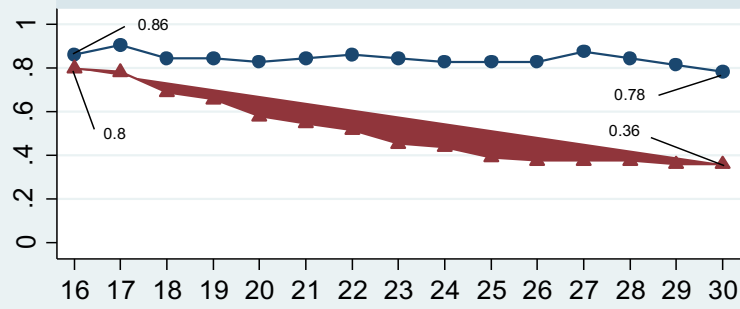

Comm, Phase II

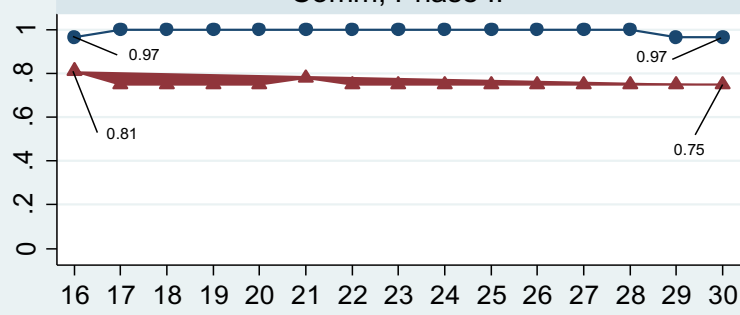

Period

$\longrightarrow$ Low Transaction Cost _ـ High Transaction Cost

Figure 1: Fraction of Participation in Phase I \& Phase II of No-Comm and Comm Sessions by Transaction Costs Treatment

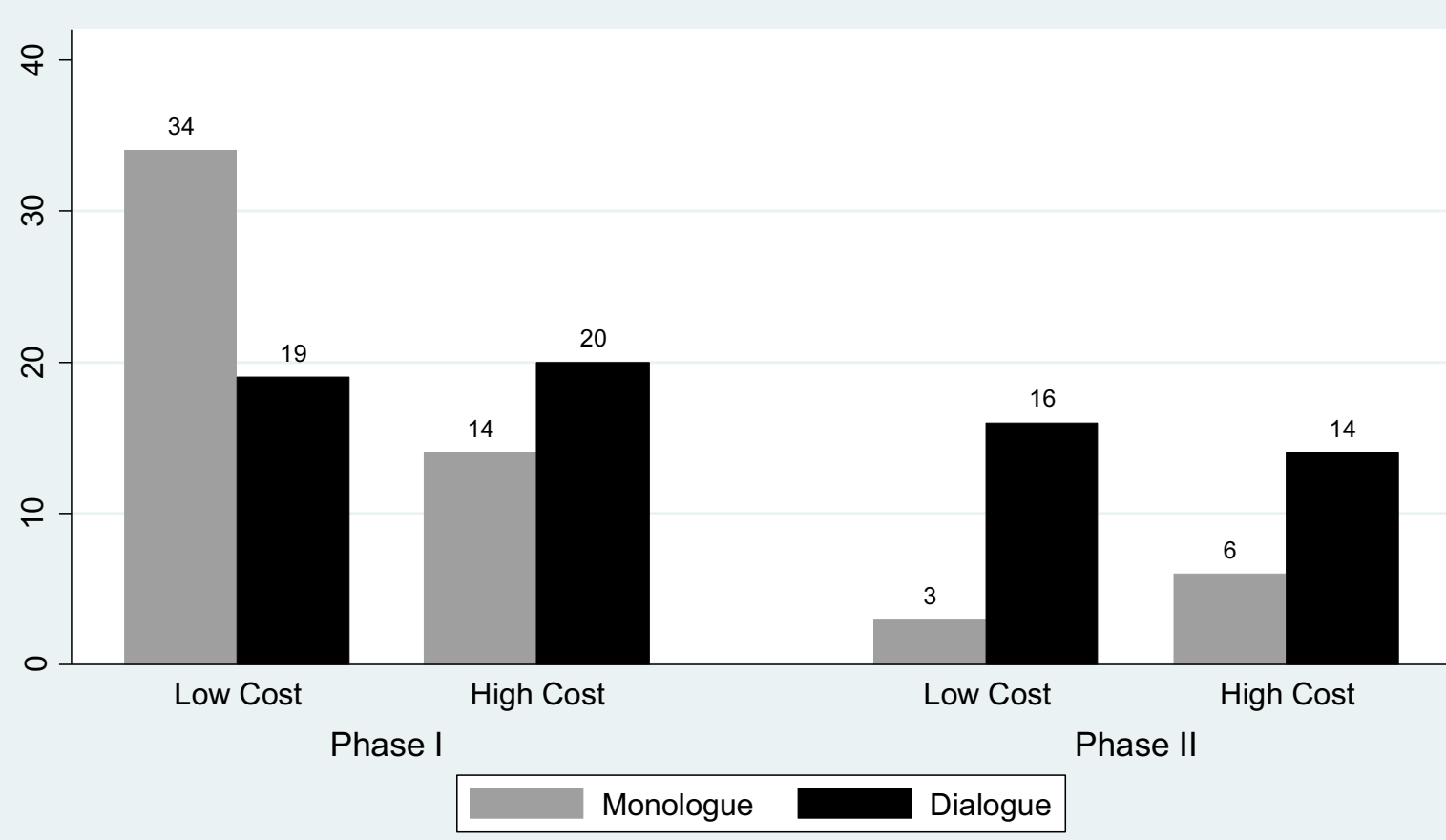

Figure 2: Frequency of Monologues and Dialogues for Comm Sessions for both Phases and Transaction Costs 


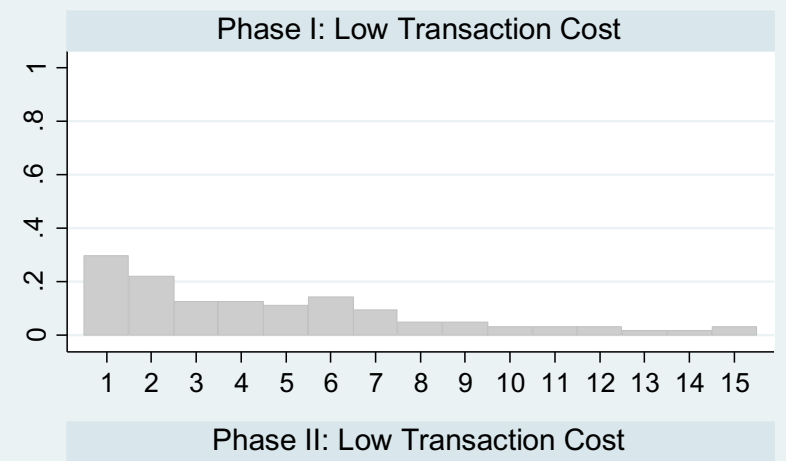

Phase I: High Transaction Cost
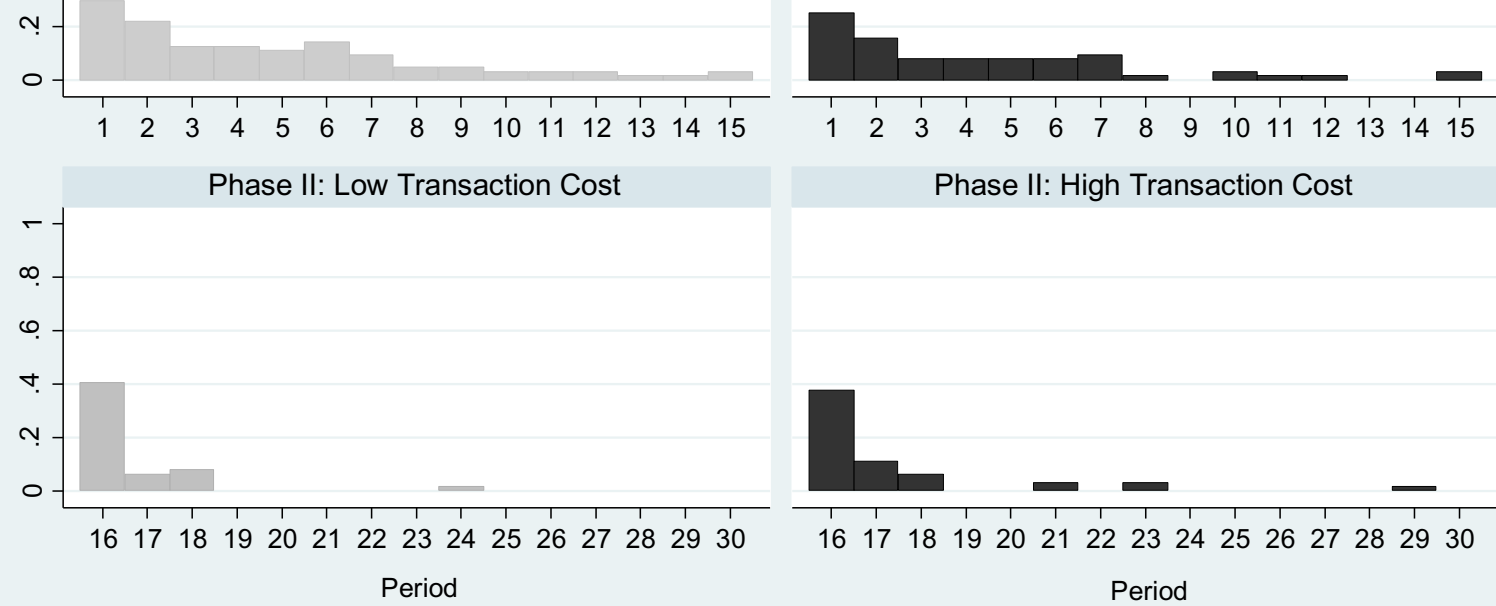

Phase II: High Transaction Cost

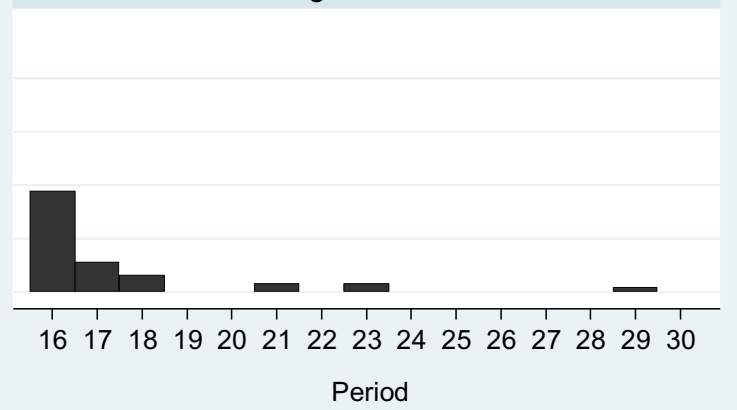

Figure 3: Fraction and Timing of Communication Channels opened with One or Both Neighbors by Phase and Transaction Cost
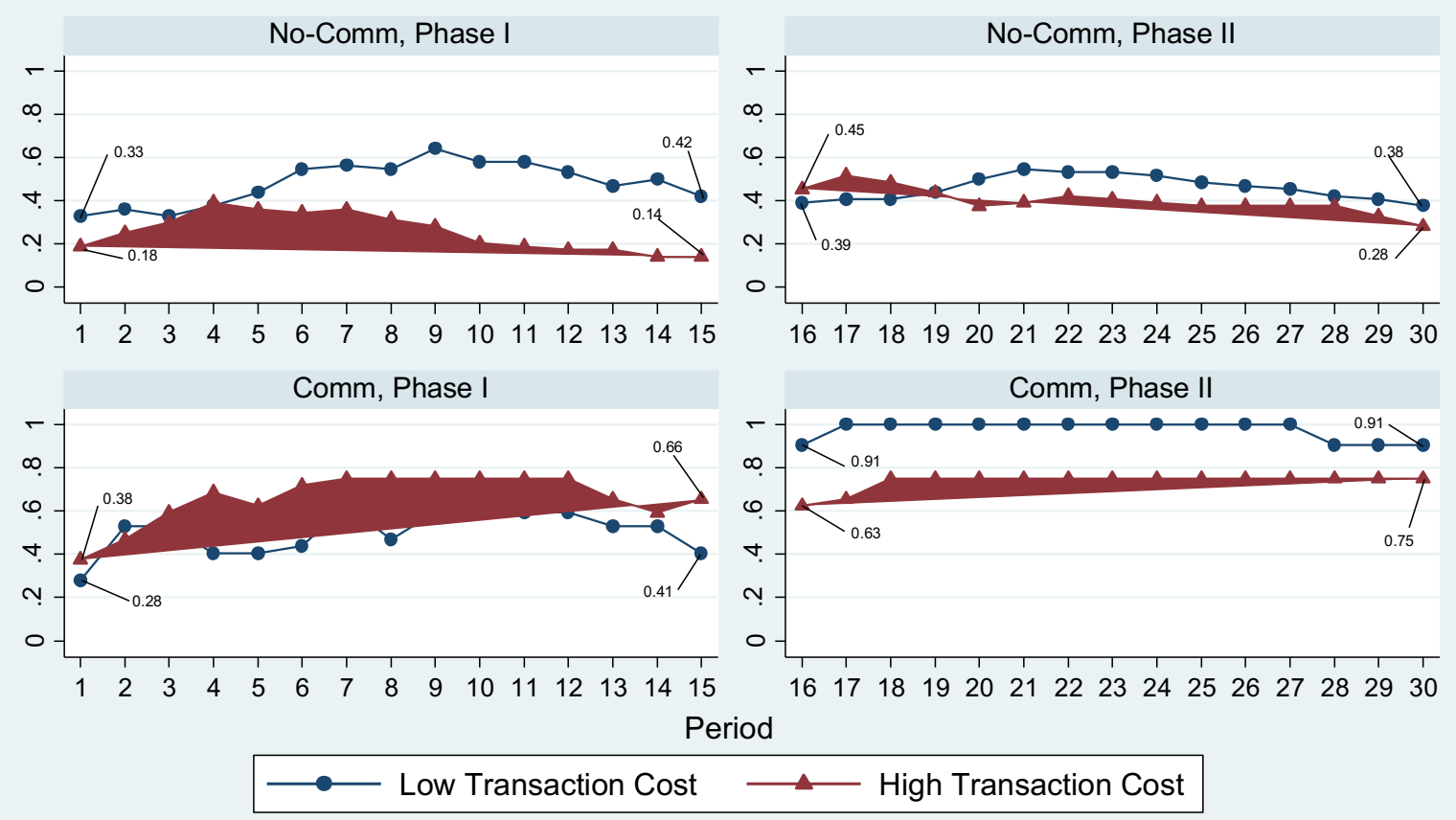

Figure 4: Fraction of Localized Efficient Coordination (player and direct neighbors choose $X$ ) in Phase I \& Phase II of No-Comm and Comm Sessions by Transaction Costs Treatment 


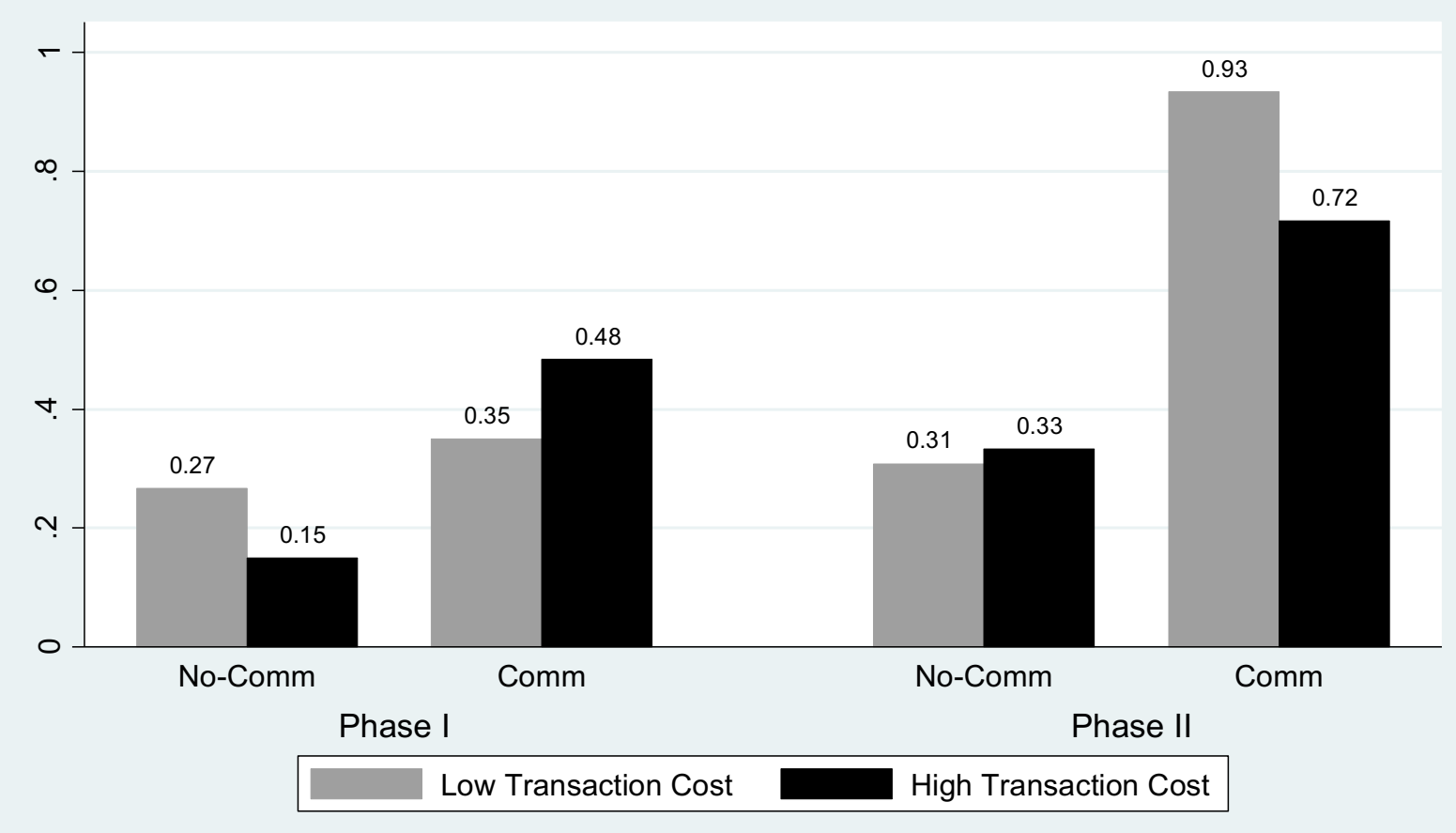

Figure 5: Perfect/Global Efficient Coordination (the whole group chooses $X$ ) in all treatments for both Phases 


\section{Appendix A}

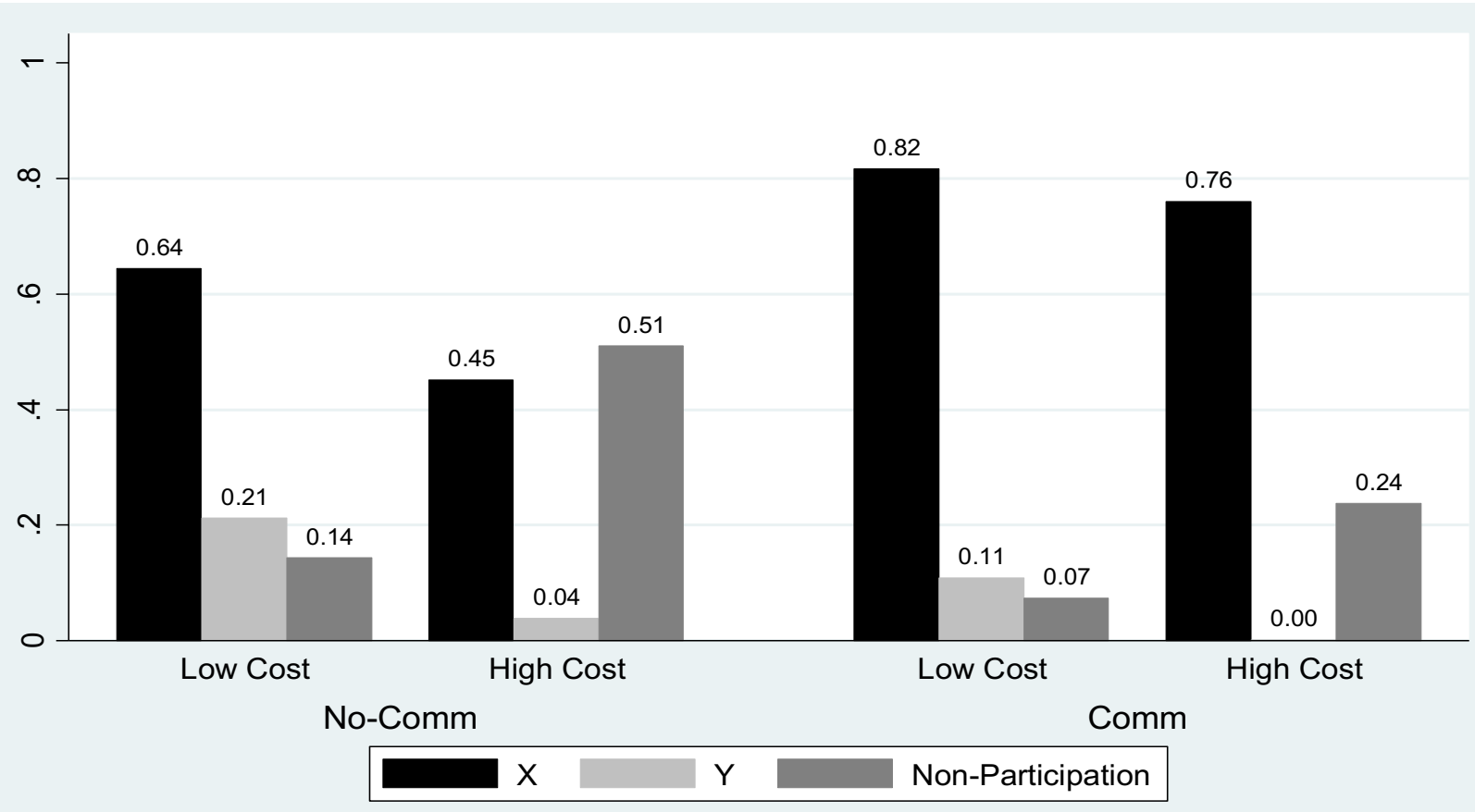

Figure I: Fraction of Choices Pooled over Time for All Treatments

No-Comm, Phase I

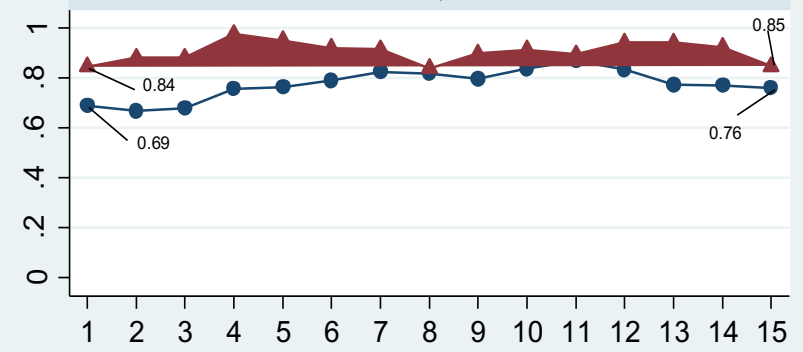

Comm, Phase I

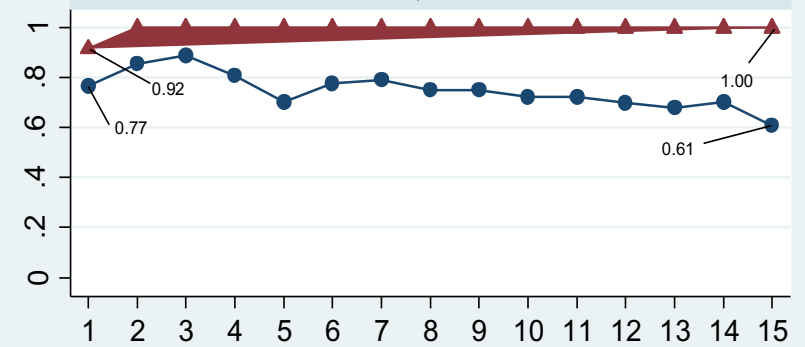

No-Comm, Phase II

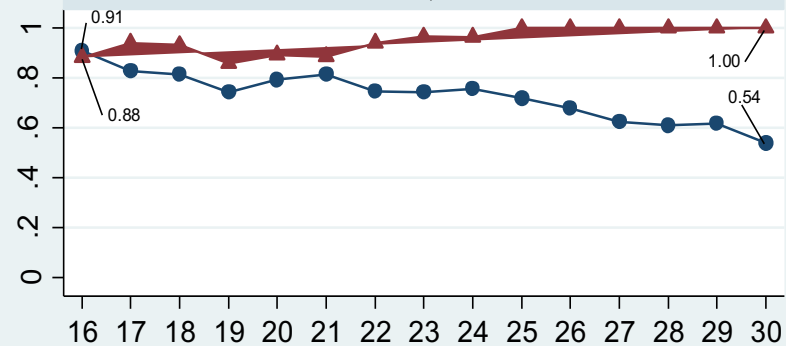

Comm, Phase II

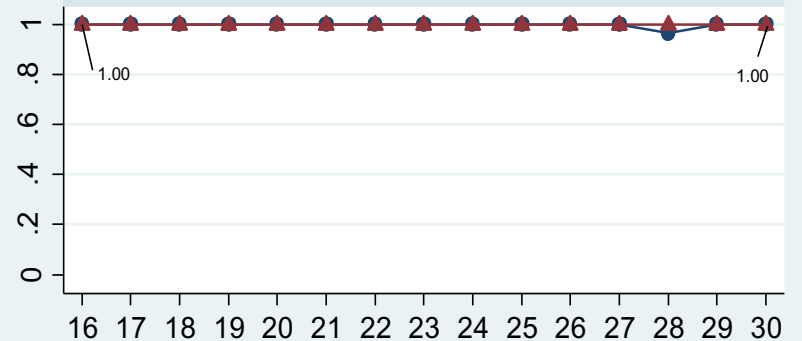

Period Low Transaction Cost $\longrightarrow$ High Transaction Cost

Figure II: Fraction of $X$ choices Conditional on Participation in Phase I \& Phase II of No-Comm and Comm Sessions 4 y Transaction Costs Treatment 


\section{Appendix B.I: Parameters used to create Payoff tables}

Income from NP $=175$

Agricultural Income from choosing X: 60

Agricultural Income from choosing $Y: 80$

Participation Payment for choosing X: 20

Participation Payment for choosing Y: 105

Agglomeration Bonus Payment for choosing X: 85

Agglomeration Bonus Payment for choosing Y: 10

High Transaction Cost: 40

Low Transaction Cost: 15 
Appendix B.II: Experimental Handout for High Cost Treatment

Circular Grid with Your Location

ID Number:

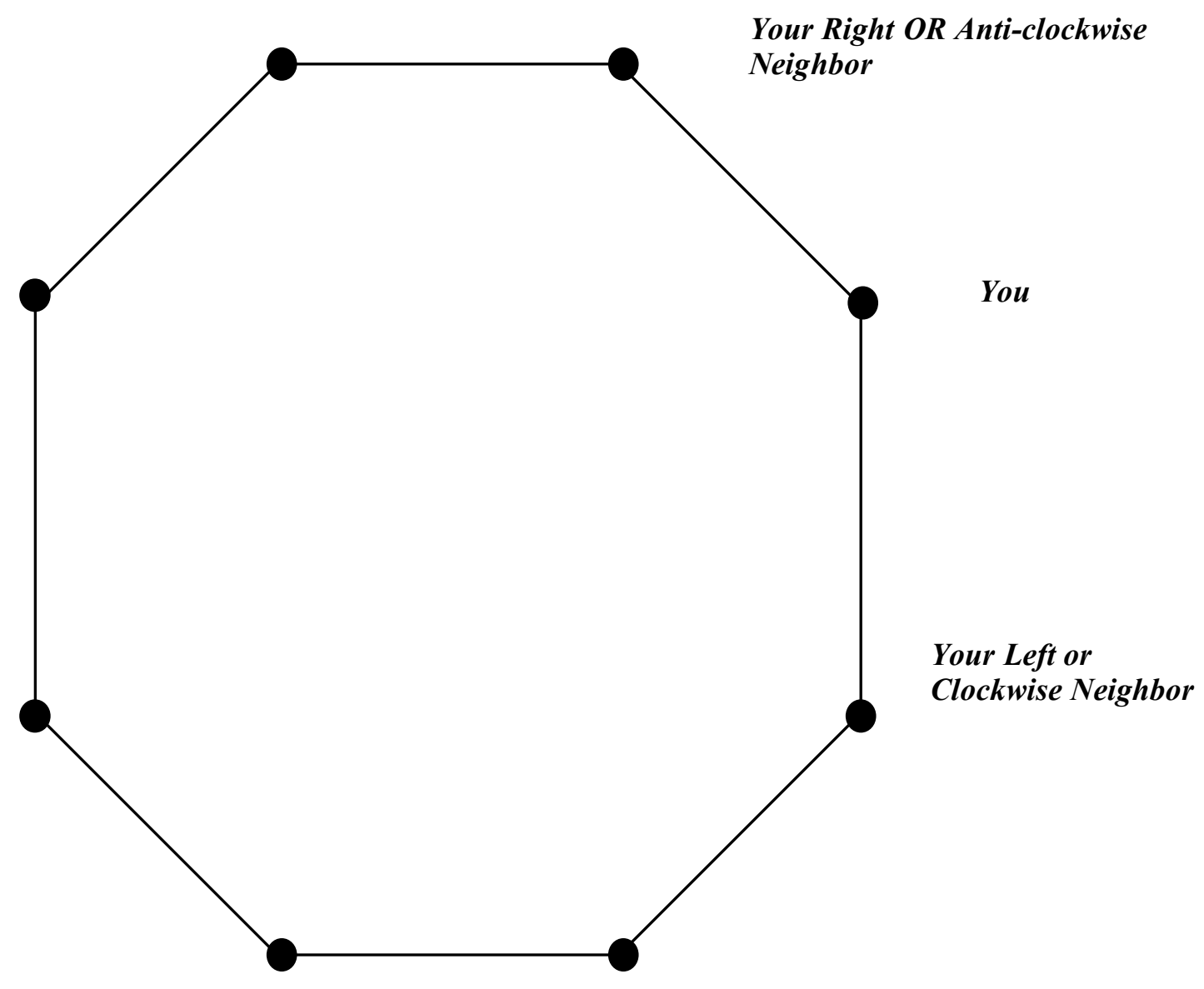

Payoff from Non-Participation (NP): 175

Cost of Participating in Land Management Program: $\underline{40}$

Payoff Table

Actions Chosen by Neighbors

\begin{tabular}{|c|c|c|c|c|c|c|}
\cline { 2 - 6 } Your Action & $\begin{array}{c}\text { Both } \\
\text { Participate } \\
\text { Choose A }\end{array}$ & $\begin{array}{c}\text { Both } \\
\text { Participate } \\
\text { and one } \\
\text { Chooses A } \\
\text { \& other B }\end{array}$ & $\begin{array}{c}\text { Both } \\
\text { Participate } \\
\text { and Choose } \\
\text { B }\end{array}$ & $\begin{array}{c}\text { Only one } \\
\text { Participates } \\
\text { \& Chooses A }\end{array}$ & $\begin{array}{c}\text { Only one } \\
\text { Participates } \\
\text { \& Chooses B }\end{array}$ & $\begin{array}{c}\text { No Neighbor } \\
\text { Participates }\end{array}$ \\
\cline { 2 - 7 } $\begin{array}{c}\text { B } \\
\text { B } \\
\text { NP (Non- } \\
\text { Participation) }\end{array}$ & 110 & 125 & 40 & 125 & 40 & 40 \\
\cline { 2 - 7 } & 145 & 155 & 165 & 145 & 155 & 145 \\
\cline { 2 - 7 } & 175 & 175 & 175 & 175 & 175 \\
\hline
\end{tabular}

All payoffs are net of participation costs 
Appendix B.III: Instructions for HLTC Sessions (Text in italics represents instructions for Comm Sessions. The $X$ and $Y$ strategies referred to in the
paper correspond to the strategy labels $A$ and $B$ in the instructions)

\section{Thank you for participating in today's experiment}

Your unique Identification number - ID for this experiment is $\mathbf{1}$. This number is private and should not be shared with anyone. You will have this ID for the next 15 periods of the experiment.

Please click "OK" when you are ready.

\section{General Information:}

This is an experiment in decision making. In today's experiment you will participate in a group decision task. In addition to a $\$ 6$ participation fee, you will be paid the money you accumulate from your choices which will be described to you in a moment. Upon the completion of the experiment, your earnings will be added up and you will be paid privately, in cash. The exact amount you will receive will be determined during the experiment and will depend on your decisions and the decisions of others. From this point forward all units of account will be in experimental francs. At the end of the experiment, experimental francs will be converted to U.S. dollars at the rate of 1 U.S. dollar for every 250 experimental francs.

If you have any questions during the experiment, please raise your hand and wait for the experimenter to come to you. Please do not talk, exclaim, and look at the computer screens of other participants during the experiment. Participants intentionally violating the rules may be asked to leave the experiment and may not be paid.

\section{Please click "Continue" when you are ready.}

\section{Today's Decision Making Task:}

The experiment will have thirty periods. In each period you will be in a group with 7 other participants. You and all the other players are arranged around a circle. The diagram of this circle is included in the handout that has been provided to you. The black dots on the circle represent your location. On this circle, you have two neighbors - a right or anti-clockwise neighbor and a left or clockwise neighbor. You will never know the identity of your neighbors. Your ID will determine who your neighbors are. Please keep in mind that every player has a different set of neighbors. Thus if you are Player 8 then your right or anti-clockwise neighbor is Player 7 and left or clockwise neighbor is Player 1. Similarly Player 7 has you as their left or clockwise neighbor and Player 6 as their right or anti-clockwise neighbor. Your ID and your neighbors will be the same for the first 15 periods of the experiment. At the beginning of Period 16 , everyone will be provided with a different ID. As a result of this ID change, your neighbors between Periods 16 and 30 will be different from those between Periods 1 and 15 . Also please remember that the person sitting at the computer terminal beside you is not your neighbor in the experiment.

During this experiment each of you will assume the role of a landowner who can participate in a land management program or opt out of it. In both cases, you will receive money for your actions. You will first be given the option to participate in this program. If you choose not to participate, you will receive a payment. Participation is costly and so you have to incur a cost to do so. Once you have incurred the cost, you will be able to take part in a group decision task which is part of the land management program. In this task, you will make a choice between two types of land use actions denoted by $\mathbf{A}$ and $\mathbf{B}$. You will 
receive a payment based on your choice of $\mathbf{A}$ or $\mathbf{B}$. Since this is a group decision task, your payment will depend on the choices made by your neighbors as well. In a moment we will give you a detailed description of how your payment will be determined.

Please note that you may decide to participate in the task but one or both of your neighbors may choose not to. Also while you decide to participate, you will not know what choices your neighbors' are making.

Please raise your hand if there are any questions otherwise click "Continue".

\section{Your Payment from Group Decision Task:}

If you choose to participate in the land management program, then in each period of the experiment, the computer will display a table such as the one shown below. This Payoff Table will be the same for everyone during a period. However the values in the cells will be different in different periods of the experiment. You will be provided with a handout containing the Payoff Table. Each number in the table corresponds to a payment (in experimental francs) resulting from a possible combination of your choice of A or B (in the row) and your neighbors' choices (in the column). Please note that all figures in the table are net of the participation cost, i.e., the participation cost has already been deducted from the payoffs. For example, suppose the participation cost is 40 and your payoff from choosing $\mathrm{A}$ and both your neighbors participating and choosing $A$ is 250 . Then your final payoff is $(250-40)=210$. This is listed in the first cell of the first row of the Payoff Table. Similarly if you select B after participation and only one of your neighbors participates and chooses B, the payoff is 195. Then your final payoff is (195 $40)=155$. The last column in the table indicates your payoffs if you participate and none of your neighbors participate.

Please note that when you will be asked to participate or not, you will know the value of the cost you have to incur. In general, your payoff from the group decision task increases when you choose the same action as your participating neighbors.

Also your payoffs are the same if 1) one or both neighbors participate and choose a different strategy than you or 2) they don't participate at all. For example, the payment to you from choosing B and both of your neighbors choosing $\mathrm{A}$ is the same as you choosing $\mathrm{B}$ and none of your neighbors participating.

\section{Communication stage:}

Before making a choice in a period about participating in the land management program, you will have the option to communicate with one or both of your neighbors. For every person you choose to communicate with, you have to pay a fee of $\mathbf{5}$ experimental francs per person. Thus if you choose to communicate with both neighbors, you have to pay a fee of 10 francs. If you choose not to communicate, you don't have to pay the fee. Please note that it is possible that you pay the fee and choose to communicate with your neighbors but they choose not to pay the fee and communicate with you. If that is the case, you will be able to send messages to the neighbors with whom you have paid to chat and they will be able to view these messages. Similarly, you may have chosen not to chat with your neighbors but one or both of them paid a fee to chat with you. They will be able to send messages to you which you will be able to view.

Your communication with the neighbor(s) will consist of messages exchanged in "chat boxes" to the left and/or right of your computer screen depending upon which neighbor you chat with. Messages sent in this chat will only be viewed by you and the neighbor you send it to. For example, if you are Player 8 and you and both your neighbors have paid the fee to communicate, the chat box on your left will contain messages you send to and receive from Player 1 and that to the right will contain messages you send to 
and receive from Player 7. You will be able to send and receive chats for 60 seconds each period. In order to send a chat to your neighbors, please type in the blue panel at the bottom of your chat box and press Enter. To send a message to your left neighbor, type your chat in the left blue panel at the base of the left chat box. Similarly use the blue panel at the base of the right chat box to send chats to your right neighbor.

Although the messages you send to each other will be recorded, your ID remains anonymous and hence all communication is anonymous to the experimenter and cannot be traced back to any subject. In sending messages, you should follow two basic rules: (1) be civil to one another and do not use profanities, (2) only use your ID to identify yourself in any manner. After the chat period is over you will be able to see the chats you have exchanged with your neighbors for 10 seconds. After these 10 seconds are over, everyone will make their participation and land management decisions. Please note that you do not learn the land management decisions of your neighbors while making your own decision.

\section{Making a choice in a period: (No-Comm)}

Once the period starts, each of you will first choose whether to participate or not. If you decide not to participate, then you will receive a fixed payoff. This payoff does not depend upon your neighbors' participation decisions. If you decide to participate, then in the next stage, you will choose strategy A or B by clicking on one of the buttons that will appear on the right of your screen. You may change your choice as often as you like, but once you click on OK your choice for that period is final.

Note that when you are making a choice, you will not know what choices others are making. Also, remember that you will never know the identity of anyone else in your group, meaning that all choices are confidential and that no one will ever know what choices you make.

At the end of each period after you have made your choices, your screen will display your choice and payoff. Information will also be provided about whether your neighbors participated and if they did, what were their choices for that period. Information on your accumulated payment through the current period will also be provided. At the end of the experiment, you will receive the sum of your payments from all thirty periods converted to real dollars. This will be paid to you privately in cash.

Before starting the experiment you will participate in a quiz on the next screen. Please note that you will not earn any money from participating in the quiz i.e. this is a non-paying period. Your answers in this quiz will not influence your final payoffs at the end of the experiment.

\section{Making a choice in a period: (Comm)}

Once the period starts and after you have made a decision to communicate (or not), each of you will first choose whether to participate or not. If you decide not to participate, then you will receive a fixed payoff. This payoff does not depend upon your neighbors' participation decisions. If you decide to participate, then in the next stage, you will choose strategy A or B by clicking on one of the buttons that will appear on the right of your screen. You may change your choice as often as you like, but once you click on $\mathbf{O K}$ your choice for that period is final.

Note that when you are making a choice, you will not know what choices others are making. Also, remember that you will never know the identity of anyone else in your group, meaning that all choices are confidential and that no one will ever know what choices you make. 
At the end of each period after you have made your choices, your screen will display your choice and payoff. Information will also be provided about whether your neighbors participated and if they did, what were their choices for that period. Information on your accumulated payment through the current period will also be provided. You will also receive information about your and your neighbors' communication decisions. At the end of the experiment, you will receive the sum of your payments from all thirty periods converted to real dollars. This will be paid to you privately in cash.

Before starting the experiment you will participate in a quiz on the next screen. Please note that you will not earn any money from participating in the quiz i.e. this is a non-paying period. Your answers in this quiz will not influence your final payoffs at the end of the experiment.

\section{Quiz:}

1. Your neighbor has the same neighbors as you. FALSE

2. Your ID and your neighbors change in Period 16 TRUE

3. What is your payoff when you chose B and both of your neighbors participate and chose A? 145

4. If you choose not to participate, then your neighbors' actions don't impact your payoff. TRUE

5. When you are deciding whether to participate or not, you will know whether your neighbors are participating or not. FALSE

6. If you decide to communicate with a neighbor, you have to pay a fee of 5. TRUE

\section{The Payoff Table: (Phase I)}

The table below represents the Payoff Table for Periods 1 to 15 . If you choose to participate in the land management program, your payoffs will be determined on the basis of this table for the next 15 periods. This Payoff Table has been provided to you in the handout. You will be provided a handout with a different Payoff Table at the end of 15 periods.

The cost of participating in the land management program for the first 15 periods is $\mathbf{4 0 .}$

If you choose not to participate, then you will receive a payoff of $\mathbf{1 7 5}$. This payoff is not dependent on the choices of your neighbors and is the same for all 30 periods.

As mentioned before, all figures in the Payoff Table are net of the participation cost, i.e., the participation cost has already been deducted from the payoffs.

Your ID for the next 15 periods is $\mathbf{1}$ and your left neighbor is Player $\mathbf{2}$ and right neighbor is Player $\mathbf{8}$.

We are now ready to begin the experiment. You will be paid on the basis of all choices you make henceforth. If you don't have any further questions, please click OK to begin.

\section{Results Table: (No-Comm)}

On the next screen you will be able to see two tables. The first table presents your choice (of A, B or NP) and the choices of your right and left neighbors for the current period. Your choice is in the cell at the center of the table. Your neighbors' choices are recorded in cells on your left and right. NP denotes a nonparticipation choice. The second table is the History Table and records your and your neighbors' choices and your profits for the current period and all periods of this experiment. Please raise your hand if there are any questions otherwise click "Continue". 


\section{Results Table: (Comm)}

On the next screen you will be able to see three tables. The first table records your and your neighbors' chat decisions for the current period. The second table presents your choice (of $A, B$ or NP) and the choices of your right and left neighbors for the current period. Your choice is in the cell at the center of the table. Your neighbors' choices are recorded in cells on your left and right. NP denotes a nonparticipation choice. The third table is the History Table and records your and your neighbors' choices and your profits for the current period and all periods of this experiment. Please raise your hand if there are any questions otherwise click "Continue".

\section{The Payoff Table: (Phase II)}

The table below represents the Payoff Table for Periods 16 to 30. If you choose to participate in the land management program, your payoffs will be determined on the basis of this table for the remaining 15 periods. The handout containing this Payoff Table will now be distributed to you.

The cost of participating in the land management program for the remaining 15 periods is $\mathbf{1 5}$.

If you choose not to participate, then you will receive a payoff of $\mathbf{1 7 5}$. This payoff is not dependent on the choices of your neighbors and is as mentioned the same for all 30 periods.

As mentioned before, all figures in the Payoff Table are net of the participation cost, i.e., the participation cost has already been deducted from the payoffs.

Please remember that your new ID is $\mathbf{4}$ and your new neighbors are Player $\mathbf{5}$ and Player 3. Everyone else has a different ID as well. Thus your neighbors between Periods 16 and 30 are different from your neighbors between Periods 1 and 15. However your neighbors during the next 15 periods of the experiment will remain the same.

Once you have received the handout, please click OK to continue. 